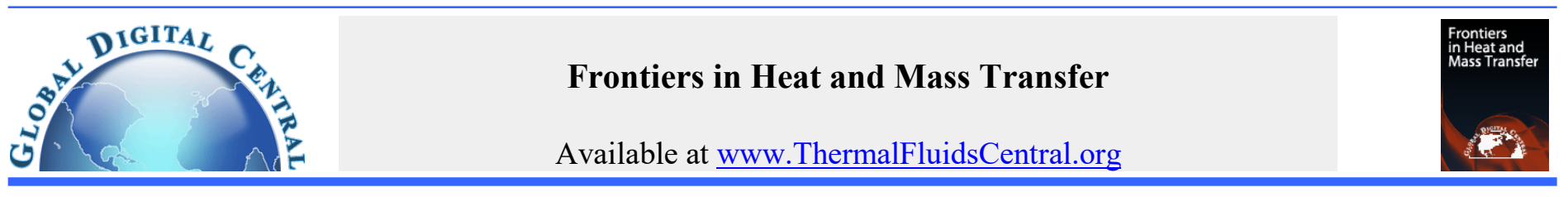

\title{
COUPLED LAMINAR NATURAL CONVECTION AND SURFACE RADIATION IN PARTIALLY RIGHT SIDE OPEN CAVITIES
}

\author{
Ravi Shankar Prasad ${ }^{a}$, S.N. Singh ${ }^{\mathrm{b}}$, Amit Kumar Gupta ${ }^{\mathrm{c}, *}$ \\ ${ }^{a}$ Heat Transfer Lab, Dept. of Mechanical Engg., IIT (ISM) Dhanbad, Jharkhand, India PIN 826004 \\ ${ }^{b}$ Department of Mechanical Engineering, IIT (ISM) Dhanbad, Jharkhand, India PIN 826004 \\ ${ }^{c}$ Department of Chemical Engineering, BIT Sindri, Dhanbad, Jharkhand, India PIN 828123
}

\begin{abstract}
This paper presents the results of numerical analysis of steady laminar natural convection and surface radiation in the two dimensional partially right side open square cavity filled with natural air $(\mathrm{Pr}=0.70)$ as the fluid medium. The cavity has left isothermal hot wall with top, bottom and right adiabatic walls. In the present study, the governing equations i.e. Navier-Stokes Equation in the stream function - vorticity form and Energy Equation are solved for a constant thermophysical property fluid under the Boussinesq approximation. For discretization of these equations, the finite volume technique is used. For the radiation calculations, the radiosity-irradiation formulation is used and the shape factors is calculated by using the Hottel's crossed-string method. The effects of openings having different dimensions at different positions in the right side wall with the other pertinent parameters like the Rayleigh Number $\left(10^{3} \leq \mathrm{Ra} \leq 10^{5}\right)$ and the surface emissivity of walls $(0.05 \leq \varepsilon \leq 0.85)$ are studied. Correlations are developed for the average convection Nusselt number and the average radiation Nusselt number at left isothermal hot wall for the different geometries of the cavity.
\end{abstract}

Keywords: Open Cavity, Optimal Cooling, Stream function, Thermal Management, Vorticity.

\section{INTRODUCTION}

Natural convection heat transfer phenomenon in the closed and open cavities has been extensively studied by the engineering researchers and the industrial scientists in the recent times. This included the well elaborated experimental studies and the numerical investigations with the several different approaches. The reasons attributed for it underlies in its important role in several engineering and practical science problems like the solar energy, aerospace engineering, cryogenics, effective cooling of internal combustion engines, cooling of electrical generators, steam generators, power plant engineering, safe design of nuclear reactors, air conditioning and refrigeration, food processing engineering, fire control engineering, chemical and metallurgical engineering, chemical and biological warfare, meteorological predictions, ocean engineering etc. For heat dissipation and cooling, the natural convection is a reasonable choice in many cases due to its inherent simplicity, reliability, quite operation and being economical.

In analyzing such problems there either an open or a closed cavity of standard geometries and orientations are considered for the sake of simplicity and convenience. This is quite an idealistic approach from the practical point of view. In most of the practical cases, there are the cavities with different geometries and openings. These are found as a very close approximation to the several practical engineering problems. Analyzing the effect of the most pertinent parameters on natural convection coupled with surface radiation in a partially side open cavity is one of the interesting realistic problem of the broad practical importance. The cooling inside a refrigerator, energy absorption in a solar energy collector, heating in the household microwave ovens, cooling of a computer CPU inside the cabinet etc. are some of the examples of convective heat transfer inside a partially side open cavities.
Such a problem of cooling by natural convection coupled with surface radiation needs to be investigated and analyzed extensively for a better understanding of its mechanism. Understanding the flow development mechanism of the natural convection flows inside the partially right side open cavities of different geometries is the prime objective of present study. The results are useful for the optimization of cooling inside a partially right side open cavities.

The motivation behind the present work is the rich and diverse literature of heat and mass transfer ranging over more than the last five decades. Sparrow and Gregg (1956) studied laminar free convection from a vertical plate with the uniform surface heat flux. Chan and Tien (1985) performed a numerical study of two-dimensional natural convection in the square open cavities. Abib and Jaluria (1988) made a numerical simulation of the buoyancy-induced flow in a partially open enclosure. Skok et al. (1991) analyzed the natural convection in a sidefacing open cavity. Balaji and Venkateshan (1994a) derived several correlations for free convection and surface radiation in a square cavity. Balaji and Venkateshan (1994b) studied the interaction of radiation with free convection in an open cavity. Mohamad (1995) made an analysis of natural convection in open cavities and slots. Rao et al. (2000) studied the conjugate mixed convection with surface radiation from a vertical plate with discrete heat source. Singh and Venkateshan (2004a) made a numerical study of natural convection with surface radiation in sidevented open cavities. Singh and Venkateshan (2004b) made a numerical investigation of natural convection with surface radiation in partially open cavities. Bilgen and Oztop (2005) studied natural convection heat transfer in partially open inclined square cavities. Hinojosa et al. (2005) made a numerical study of transient and steady-state natural convection and surface thermal radiation in a horizontal square open cavity. The above research work underlines the importance of natural convection and surface radiation heat transfer in a practical cooling problem. The effect 
of surface radiation on natural convection cooling process is also analyzed in the above studies.

Kasayapanand (2007) developed a numerical model of natural convection in partially open square cavities under electrical field. Bilgen and Muftuoglu (2008) studied natural convection in an open square cavity with slots. Nouanegue et al. (2008) studied the conjugate heat transfer by natural convection, conduction and radiation in open cavities. Singh (2008) made a numerical study of combined natural convection, conduction and surface radiation heat transfer in open top, side vented cavities. Wu et al. (2008) investigated the effect of a large top wall temperature on the natural convection plume along a heated vertical wall in a square cavity. Gnanasekaran and Balaji (2011) developed a correlation for Nusselt number under turbulent mixed convection using transient heat transfer experiments. Panda and Prasad (2011) studied conjugate heat transfer from a flat plate with shower head impinging jets. Gonzalez et al. (2012) made a numerical study of heat transfer by natural convection and surface thermal radiation in an open cavity receiver. Palafox (2012) made a numerical study of the natural convection in a two-dimensional partially open tilted cavity. Karami et al. (2014) optimized the laminar free convection in a horizontal cavity consisting of flow diverters using imperialist competitive algorithm (ICA). Martyushev and Sheremet (2014) studied conjugate natural convection combined with surface thermal radiation in an air filled cavity with internal heat source. Gonzalez et al. (2015) made a theoretical and experimental study of natural convection with surface thermal radiation in a side open cavity. Miroshnichenko and Sheremet (2015) made a numerical simulation of turbulent natural convection combined with surface thermal radiation in a square cavity. Singh and Singh (2015) investigated conjugate free convection with surface radiation in an open top cavity. Joo and Kim (2016) made thermal optimization of vertically oriented, internally finned tubes in natural convection. Li and Tong (2016) studied the natural convective heat transfer in the inclined rectangular cavities with low width-to-height ratios. Sheremet and Miroshnichenko (2016) analyzed the effect of surface radiation on transient natural convection in a wavy-walled cavity. Hati et al. (2017) made an optimal natural convection heat transfer improvement by combining periodic heating temperature, cavity inclination and nanofluid. Karatas and Derbentli (2017) analyzed the three-dimensional natural convection and radiation in a rectangular cavity with one active vertical wall. Saglietti et al. (2017) studied the adjoint optimization of natural convection problems in differentially heated cavity. Bangian-Tabrizi and Jaluria (2018) proposed an optimization strategy for the inverse solution of a convection heat transfer problem. Lugarini et al. (2018) studied natural convection and surface radiation in a heated wall with the $\mathrm{C}$ shaped fracture. Miroshnichenko and Sheremet (2018) studied the turbulent natural convection combined with thermal surface radiation inside an inclined cavity having local heater. Poovanan et al. (2018) suggested the heat sink elimination and optimization by natural convection method. Prasad et al. (2018) proposed a systematic approach for optimal positioning of heated side walls in a side vented open cavity under natural convection and surface radiation. These research works analyze the different practical situations involved with the cooling by natural convection and surface radiation. These analysis are based on the different practical problems and their proposed optimal solutions.

Karami et al. (2014), Joo and Kim (2016), Hati et al. (2017), Bangian-Tabrizi and Jaluria (2018) and Poovanan et al. (2018) proposed the different algorithms for the optimization of cooling by natural convection. The optimization of position of heat sources has been performed by the many researchers. Several studies of natural convection with surface radiation in different cavities has been performed to maximize the cooling of different heat sources. But the optimization of size and position of openings in the cavities has been less studied by the researchers so far.

Natural convection and surface radiation in cavities having different geometries and openings has been studied by the different researchers. The present literature survey underlines the need for an extensive study of the effect of different opening in the side wall of cavity on the cooling of the heat sources inside the cavity. This would be useful in understanding the process of coupled natural convection with surface radiation in the partially right side open cavities. The right side wall has openings of different sizes at different positions in the different cases. These openings in different cases influences the cooling of the left side hot wall by natural convection and surface radiation differently. The comparison of the effects of the different partial right side wall openings having different sizes at different positions on the cooling of left side hot wall by coupled natural convection and surface radiation is made in this paper for the completeness of such studies. Such a comparison has not been performed by the other researchers so far. Correlations are developed for the average convection Nusselt number and the average radiation Nusselt numbers for the different geometries of cavity.

There are several research papers discussing the pure natural convection as well as the coupled natural convection with surface radiation in the right side open cavities. For the completeness of such studies, the comparison between the coupled natural convection and surface radiation in the cavities having the different types of right side wall openings is needed. The effect of size and position of opening is studied in this research paper with the objective of optimizing the cooling of left side hot isothermal wall. This paper presents an analysis of natural convection and surface radiation in cavities with the different right side wall openings, which provides an insight for understanding the mechanism of natural convection in such cavities in a better convincing way. This is helpful in analyzing and predicting the natural convection and surface radiation in the cavities having the openings of different dimensions at different positions. On the basis of this comparison the optimum position and size of opening in a practical situation may be determined. The results obtained are useful and important for the optimization of cooling inside the side open cavities leading to optimal compact design of the devices having the heat generating components.

\section{MATHEMATICAL FORMULATION}

\subsection{Formulation for Natural Convection}

The two-dimensional steady incompressible laminar natural convection heat transfer in an open rectangular cavity having height ' $\mathrm{H}$ ' and horizontal width ' $d$ ' is considered as shown in Fig. 1. The sizes of lower vent wall, middle port and upper vent wall are w1, w2 and w3 respectively. From the geometry, w1 $+\mathrm{w} 2+\mathrm{w} 3=\mathrm{H}$.

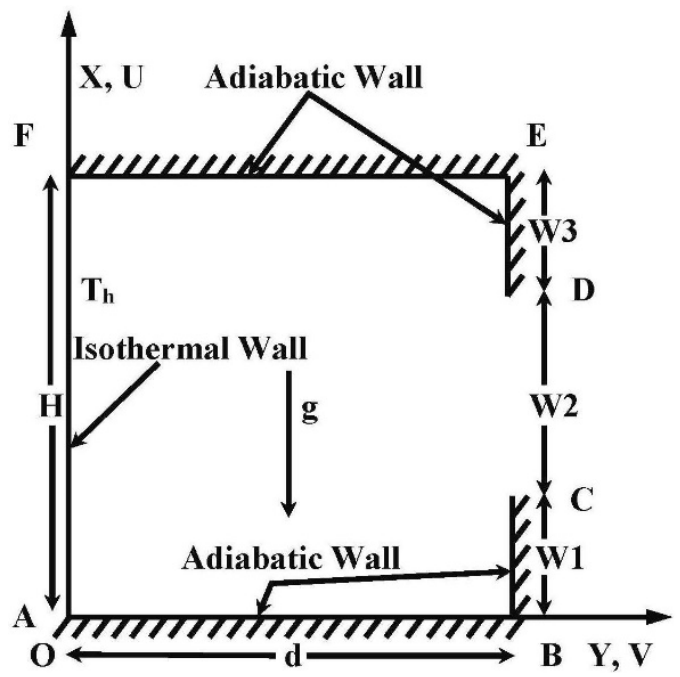

Fig. 1 Problem geometry showing the computational domain.

The governing equations Eqs. (1), (2) amd (3) in stream function $(\psi)$ - vorticity $(\omega)$ form, for a constant property fluid under the Boussinesq approximation, in the non-dimensional form are: 
$U \frac{\partial \omega}{\partial X}+V \frac{\partial \omega}{\partial Y}=\operatorname{Pr} \cdot\left[\frac{\partial^{2} \omega}{\partial X^{2}}+\frac{\partial^{2} \omega}{\partial Y^{2}}\right]-R a \frac{\partial \theta}{\partial Y}$

$\frac{\partial^{2} \psi}{\partial X^{2}}+\frac{\partial^{2} \psi}{\partial Y^{2}}=-\operatorname{Pr} \omega$

$U \frac{\partial \theta}{\partial X}+V \frac{\partial \theta}{\partial Y}=\frac{\partial^{2} \theta}{\partial X^{2}}+\frac{\partial^{2} \theta}{\partial Y^{2}}$

where $U=\frac{\partial \psi}{\partial Y}, V=-\frac{\partial \psi}{\partial X}$ and $\omega=\frac{\partial V}{\partial X}-\frac{\partial U}{\partial Y}$

The variables normalized with their normalized value are shown in Eq. (4).

$X=\frac{x}{d}, Y=\frac{y}{d}, U=\frac{u d}{\alpha}, V=\frac{v d}{\alpha}$,

$\Psi=\frac{\psi^{\prime}}{\alpha}, \omega=\frac{\omega^{\prime} d^{2}}{v}, \theta=\frac{T-T_{\infty}}{T_{h}-T_{\infty}}$

\subsection{Formulation for Surface Radiation}

The radiosity-irradiation formulation is used to describe the surface radiation (Singh and Venkateshan, 2004a). The walls are assumed to be diffuse and gray i.e. independent of direction and wavelength. For an elemental area on the boundary of the cavity, the non-dimensional radiosity is given by the Eq. (5).

$J_{i}=\varepsilon_{i}\left(T_{i} / T_{h}\right)^{4}+\left(1-\varepsilon_{i}\right) \sum_{j=1}^{2(m+n-2)} F_{i j} J_{j}$ where $i=1,2(m+n-2)$

Here the view factors $F_{i j}$ are calculated using the Hottel's crossed string method.

\subsection{Boundary Conditions}

The prime interest of the present study is to study the flow and temperature field in the computational domain enclosed by the cavity. In the present study, the computational domain enclosed by the cavity as shown in Fig. 1 is considered. The appropriate boundary conditions applicable to this computational domain are specified and used.

The stream function and vorticity boundary conditions specified in Eqs. (6) to (11) on each of the boundary are based on several research papers by Balaji and Venkateshan (1994a, 1994b), Rao et al. (2000) and Singh and Venkateshan (2004a). The boundary conditions in terms of the velocities $\mathrm{U}$ and $\mathrm{V}$ are mentioned for clarity and simplicity.

For the left isothermal hot wall:

$\begin{array}{lll}0<X<A, & Y=0, & U=0, V=0 \text { or } \psi=0, \\ \omega=-\frac{1}{\operatorname{Pr}} \frac{\partial^{2} \psi}{\partial Y^{2}}, & \theta=1 & \end{array}$

For the adiabatic bottom wall:

$X=0, \quad 0<Y<1, \quad U=0, V=0$ or $\psi=0$,

$\omega=-\frac{1}{P r} \frac{\partial^{2} \psi}{\partial X^{2}}, \quad-\frac{\partial \theta}{\partial X}=N_{r c}(J-G)$

For right side bottom adiabatic vent wall:

$0<X<W 1, \quad Y=1, \quad U=0, V=0$ or $\psi=0$,

$\omega=-\frac{1}{\operatorname{Pr}} \frac{\partial^{2} \psi}{\partial Y^{2}}, \quad \frac{\partial \theta}{\partial Y}=N_{r c}(J-G)$

For right side top adiabatic vent wall:

$W 2<X<A, \quad Y=1, \quad U=0, V=0$ or $\psi=0$,

$\omega=-\frac{1}{\operatorname{Pr}} \frac{\partial^{2} \psi}{\partial Y^{2}}, \quad \frac{\partial \theta}{\partial Y}=N_{r c}(J-G)$

For the adiabatic top wall:

$$
\begin{array}{lll}
X=A, & 0<Y<1, & U=0, V=0 \text { or } \psi=0, \\
\omega=-\frac{1}{\operatorname{Pr}} \frac{\partial^{2} \psi}{\partial X^{2}}, & \frac{\partial \theta}{\partial X}=N_{r c}(J-G) &
\end{array}
$$

Along the open boundary CD,

$$
\begin{aligned}
& Y=1, \quad W 1<X<W 2, \quad \omega=0, \quad \theta_{\text {in }}=0, \\
& \frac{\partial U}{\partial X}=-\frac{\partial V}{\partial Y}=\frac{\partial^{2} \psi}{\partial X \partial Y}=0
\end{aligned}
$$

Here in this case neither the vertical velocity $(U)$ nor the horizontal velocity (V) is assumed to be zero. This is a mixed boundary condition providing the smooth variation of the two velocity components. By the definition of stream function, the equation of continuity is satisfied everywhere, but this smoothness boundary condition makes the continuity equation satisfied everywhere as well as makes both of the derivative terms identically zero along the opening in the right wall.

Rao et al. (2000) have implemented this boundary condition in studying the problem of laminar mixed convection from heated vertical plate and found this boundary condition the most appropriate. Singh and Venkateshan (2004a) compared this boundary condition with the several other possible boundary conditions for studying the natural convection and surface radiation in side vented open cavities and found it to be the most appropriate.

\section{METHOD OF SOLUTION}

The governing Eqs. (1), (2) and (3) are transformed into finite difference equations using the finite volume based finite difference method. Then the Gauss-Seidel iterative procedure is used to solve the algebraic equations obtained. The set of discretized equations obtained are solved by using a line-by-line procedure of the Tri-diagonal matrix algorithm (TDMA) or Thomas algorithm. A computer code for a FORTRAN platform is developed for solving the discretized equations. An optimum grid size of $51 \times 51$ is selected for the computational domain on the basis of grid sensitivity analysis or grid independence analysis presented later (Singh and Venkateshan, 2004a). A cosine function has been chosen to generate the grids along both the $\mathrm{X}$ and $\mathrm{Y}$ directions in computational domain of the cavity. These cosine grids are very fine near the solid boundaries, where the gradients are very steep, while they are relatively coarser in the remaining part of the domain as shown in Fig. 2. Derivative boundary conditions are implemented by three point formulae using the Lagrangian polynomial. The integration required in calculations is performed by using the Simpson's one-third rule for the non-uniform step size.

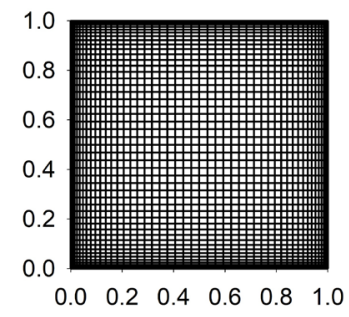

Fig. 2 Typical grid patterns used in the analysis. $A=1$, Grid size $=$ $51 \times 51$.

Upwinding has been used for representing the advection terms to ensure the stable and convergent solutions. Under relaxation with a relaxation parameter 0.1 is used for all the equations except for the radiosity equations, where the relaxation parameter 0.5 is used.

A convergence criterion $(\delta)$ in the percentage form has been defined as Eq. (12).

$\delta=\left|\left(\zeta_{\text {new }}-\zeta_{\text {old }}\right) / \zeta_{\text {new }}\right| X 100$, 
where $\zeta$ is any dependent variable like $\psi, \omega, \theta, \mathrm{J}$ and $\mathrm{G}$, over which the convergence test is applied. Here the subscripts "old" and "new" refers to the first and second values of $\zeta$ calculated in the any two successive iterations. A convergence criterion of $0.1 \%$ or $10^{-3}$ has been used for stream function, vorticity and temperature, whereas the convergence criterion of $0.01 \%$ or $10^{-4}$ has been used for the radiosity.

\section{RESULTS AND DISCUSSION}

The Table 1 shows the range of parameters considered in the present study. The results are presented with the objective of analytical comparison between the different cases considered. A grid sensitivity study is presented for the determination of optimum grid size for the present study.

Table 1 Range of parameters considered for the present study.

\begin{tabular}{|l|l|}
\hline Parameters & Range \\
\hline Rayleigh Number, $\mathrm{Ra}_{\mathrm{H}}$ & $10^{3}-10^{5}$ \\
\hline Conduction-radiation parameter, $\mathrm{N}_{\mathrm{rc}}$ & 42.261 \\
\hline Emissivity, $\varepsilon$ & $0.05-0.85$ \\
\hline Temperature ratio, $\mathrm{T}_{\mathrm{R}}$ & 0.854 \\
\hline Aspect Ratio, $\mathrm{A}$ & 1 \\
\hline
\end{tabular}

\subsection{Grid Sensitivity Study}

A grid sensitivity study or grid independence study is performed to find the optimum grid size as suggested by Singh and Venkateshan (2004a). In each case of present problem, there is an interaction between natural convection and surface radiation. The grid sizes affect the convection and radiation Nusselt numbers differently. Hence in order to determine the optimum grid size, the analysis of the effect of increasing grid size on both the convection Nusselt number and radiation Nusselt number must be made. Here the grid sensitivity analysis is done into two parts. In the first part ' $\mathrm{n}$ ' is fixed and in the second part ' $\mathrm{m}$ ' is fixed at a moderate value of 31 . Here for the grid sensitivity analysis, the convection Nusselt number, radiation Nusselt number and total Nusselt number at the uniformly heated left isothermal hot wall is considered.

Here in the Table 2, it is observed that the change in $\overline{\mathrm{Nu}}_{\mathrm{R}}$ and $\overline{\mathrm{Nu}}_{\mathrm{T}}$ at grid size greater than $41 \times 31$ is negligible. The change in $\overline{\mathrm{Nu}}_{\mathrm{C}}, \overline{\mathrm{Nu}}_{\mathrm{R}}$ and $\overline{\mathrm{Nu}}_{\mathrm{T}}$ is less than $1 \%$ at grid size greater than $51 \times 31$. Hence, $\mathrm{m}=$ 51 is selected.

In the Table 3 it is observed that the change in $\overline{\mathrm{Nu}}_{\mathrm{C}}, \overline{\mathrm{Nu}}_{\mathrm{R}}$ and $\overline{\mathrm{Nu}}_{\mathrm{T}}$ is less than $2 \%$ at grid size $31 \times 51$ and higher. Further it is also observed that with $\mathrm{n}=51$, the percentage change in $\overline{\mathrm{Nu}}_{\mathrm{R}}$ is less than $2 \%$ with respect to its mean value. The change in various parameters like the bottom wall temperature, top wall temperature and vertical air velocity at different horizontal sections is not significant with the further increase in the grid size by increasing $n$. Thus, $n=51$ may be selected without affecting the results significantly. Hence, $\mathrm{n}=51$ is selected.

Table 2 Grid independence study for varied $\mathrm{m}, \mathrm{n}=31$ (For case $\mathrm{A}=1$, $\mathrm{N}_{\mathrm{rc}}=42.261, \mathrm{Pr}=0.70, \mathrm{Ra}_{\mathrm{H}}=1.0 \times 10^{5}, \mathrm{~T}_{\mathrm{R}}=0.854, \mathrm{~W} 1=0.250, \mathrm{~W} 2=$ $0.500, \mathrm{~W} 3=0.250, \varepsilon=0.85)$.

\begin{tabular}{|l|l|l|l|l|l|l|}
\hline$m \times n$ & $\overline{N u}_{C}$ & $\overline{N u}_{R}$ & $\overline{N u}_{T}$ & $\begin{array}{l}\% \\
\text { Change } \\
\text { in } \overline{N u}_{C}\end{array}$ & $\begin{array}{l}\% \\
\text { Change } \\
\text { in } \overline{N u}_{R}\end{array}$ & $\begin{array}{l}\% \\
\text { Change } \\
\text { in } \overline{N u}_{T}\end{array}$ \\
\hline $21 \times 31$ & 3.00 & 7.40 & 10.40 & -- & -- & -- \\
\hline $31 \times 31$ & 2.84 & 7.34 & 10.18 & 5.33 & 0.81 & 2.12 \\
\hline $41 \times 31$ & 2.77 & 7.33 & 10.10 & 2.46 & 0.14 & 0.79 \\
\hline $51 \times 31$ & 2.74 & 7.33 & 10.07 & 1.08 & 0 & 0.30 \\
\hline $61 \times 31$ & 2.72 & 7.33 & 10.05 & 0.73 & 0 & 0.20 \\
\hline $71 \times 31$ & 2.71 & 7.32 & 10.03 & 0.37 & 0.14 & 0.20 \\
\hline $81 \times 31$ & 2.70 & 7.32 & 10.02 & 0.37 & 0 & 0.10 \\
\hline $91 \times 31$ & 2.70 & 7.33 & 10.03 & 0 & 0.14 & 0.10 \\
\hline $101 \times 31$ & 2.70 & 7.33 & 10.03 & 0 & 0 & 0 \\
\hline
\end{tabular}

Table 3 Grid independence study for varied $\mathrm{n}, \mathrm{m}=31$ (For case $\mathrm{A}=1$, $\mathrm{N}_{\mathrm{rc}}=42.261, \mathrm{Pr}=0.70, \mathrm{Ra}_{\mathrm{H}}=1.0 \times 10^{5}, \mathrm{~T}_{\mathrm{R}}=0.854, \mathrm{~W} 1=0.250, \mathrm{~W} 2=$ $0.500, \mathrm{~W} 3=0.250, \varepsilon=0.85)$.

\begin{tabular}{|l|l|l|l|l|l|l|}
\hline$m \times n$ & $\overline{N u}_{C}$ & $\overline{N u}_{R}$ & $\overline{N u}_{T}$ & $\begin{array}{l}\% \\
\text { Change } \\
\text { in } \overline{N u}_{C}\end{array}$ & $\begin{array}{l}\% \\
\text { Change } \\
\text { in } \overline{N u}_{R}\end{array}$ & $\begin{array}{l}\% \\
\text { Change } \\
\text { in } \overline{N u}_{T}\end{array}$ \\
\hline $31 \times 21$ & 2.97 & 7.86 & 10.83 & -- & -- & -- \\
\hline $31 \times 31$ & 2.84 & 7.34 & 10.18 & 4.38 & 6.62 & 6.00 \\
\hline $31 \times 41$ & 2.70 & 6.91 & 9.61 & 4.93 & 5.86 & 5.60 \\
\hline $31 \times 51$ & 2.73 & 6.78 & 9.51 & 1.11 & 1.88 & 1.04 \\
\hline $31 \times 61$ & 2.70 & 6.65 & 9.35 & 1.10 & 1.92 & 1.68 \\
\hline $31 \times 71$ & 2.69 & 6.55 & 9.24 & 0.37 & 1.50 & 1.18 \\
\hline $31 \times 81$ & 2.70 & 6.47 & 9.17 & 0.37 & 1.22 & 0.76 \\
\hline $31 \times 91$ & 2.71 & 6.44 & 9.15 & 0.37 & 0.46 & 0.22 \\
\hline $31 \times 101$ & 2.70 & 6.39 & 9.09 & 0.37 & 0.78 & 0.66 \\
\hline
\end{tabular}

Thus, on careful observation of both the tables 2 and 3 , we find that the grid size $51 \times 51$ is optimum for the present problem. Any further increase in the grid size increases the computational work manifolds without more significant improvement in the accuracy of results.

\subsection{Code Validation}

The results of present study are compared with the several numerical and experimental results and found to have a good agreement with them.

\section{Comparison with the Results of Chan and Tien (1985)}

Chan and Tien (1985) presented the results for the two dimensional laminar natural convection in a right side open cavity. In this case, $\mathrm{W} 1=$ $\mathrm{W} 3=0, \mathrm{~W} 2=1.0$ and the radiation heat transfer is neglected. The value of average convection Nusselt number $\overline{\mathrm{Nu}}_{\mathrm{C}}$ at the left isothermal hot wall under similar conditions, $\operatorname{Pr}=1.0, \mathrm{~A}=1$ and $\mathrm{Ra}_{\mathrm{H}}=10^{3}$ is found to be 1.14 and 1.07 for the present study and the results of Chan and Tien respectively. The other values of $\overline{\mathrm{Nu}}_{\mathrm{C}}$ for the two studies under the similar conditions and at the different Rayleigh numbers are shown in Table 4 and Fig. 3 and a very good agreement is observed between the results of these two studies.

Table 4 Comparison between the results of Chan and Tien (1985) and Palafox (2012).

\begin{tabular}{|l|l|l|l|l|}
\hline $\begin{array}{l}\text { Aspect } \\
\text { Ratio, } \\
A\end{array}$ & $\begin{array}{l}\text { Rayleigh } \\
\text { Number, } \\
\text { RaH }\end{array}$ & $\begin{array}{l}\overline{\mathrm{Nu}}_{C} \text { for } \\
\text { the present } \\
\text { study }\end{array}$ & $\begin{array}{l}\overline{\mathrm{Nu}}_{C} \text { for the } \\
\text { results of } \\
\text { Chan and } \\
\text { Tien }(1985)\end{array}$ & $\begin{array}{l}\overline{\mathrm{Nu}}_{C} \text { for the } \\
\text { results of } \\
\text { Palafox } \\
\text { (2012) }\end{array}$ \\
\hline 1.0 & $10^{3}$ & 1.14 & 1.07 & 1.28 \\
\hline 1.0 & $10^{4}$ & 2.87 & 3.41 & 3.57 \\
\hline 1.0 & $10^{5}$ & 6.74 & 7.69 & 7.75 \\
\hline 1.0 & $10^{6}$ & 15.60 & 15.0 & 15.11 \\
\hline
\end{tabular}

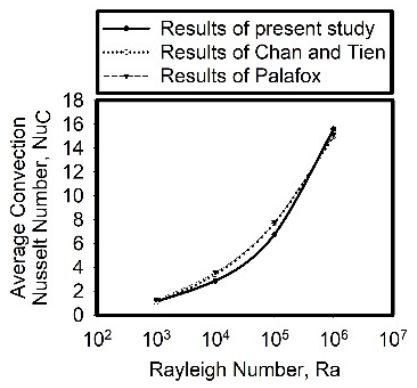

Fig. 3 Validation with Chan and Tien (1985) and Palafox (2012).

\section{Comparison with the Results of Palafox (2012)}

Palafox (2012) presented the results of a numerical study of pure natural convection in a two dimensional partially open tilted cavity. In the case 
of completely open cavity and an angle of tilt $90^{\circ}$, the cavity in the referred work is geometrically similar to the side open cavity of present case with $\mathrm{W} 1=\mathrm{W} 3=0$ and $\mathrm{W} 2=1$. In the case of pure natural convection, the radiation heat transfer is neglected and the value of average convection Nusselt number $\overline{\mathrm{Nu}}_{\mathrm{C}}$ at the left isothermal hot wall is found at $\operatorname{Pr}=1.0$ and different Rayleigh numbers. The results of present study are compared with the results of Hinojosa and a very good agreement is observed between the results of these two studies under similar conditions as shown in Table 4 and Fig. 3.

\section{Comparison with the Results of Mohamad (1995)}

Mohamad (1995) presented the results of a numerical analysis of pure natural convection in a two dimensional open tilted cavity. For the angle of tilt $90^{\circ}$ and aspect ratio $\mathrm{A}=1.0$, it has a geometry similar to the side open cavity of present case with $\mathrm{W} 1=\mathrm{W} 3=0$ and $\mathrm{W} 2=1$. The average convection Nusselt number $\overline{\mathrm{Nu}}_{\mathrm{C}}$ at the left isothermal hot wall is found at different Rayleigh numbers neglecting the radiation heat transfer inside the cavity. The results obtained for the present study is compared with the results of Mohamad and there a very good agreement is observed as shown in Table 5 and Fig. 4.

Table 5 Comparison between the results of Mohamad (1995).

\begin{tabular}{|l|l|l|l|}
\hline $\begin{array}{l}\text { Aspect } \\
\text { Ratio, } A\end{array}$ & $\begin{array}{l}\text { Rayleigh } \\
\text { Number, } R a_{H}\end{array}$ & $\begin{array}{l}\overline{N u}_{C} \text { for the } \\
\text { present study }\end{array}$ & $\begin{array}{l}\overline{N u}_{C} \text { for the results } \\
\text { of Mohamad (1995) }\end{array}$ \\
\hline 1.0 & $10^{3}$ & 1.14 & 1.31 \\
\hline 1.0 & $10^{4}$ & 2.85 & 3.44 \\
\hline 1.0 & $10^{5}$ & 6.46 & 7.41 \\
\hline 1.0 & $10^{6}$ & 14.19 & 14.36 \\
\hline
\end{tabular}

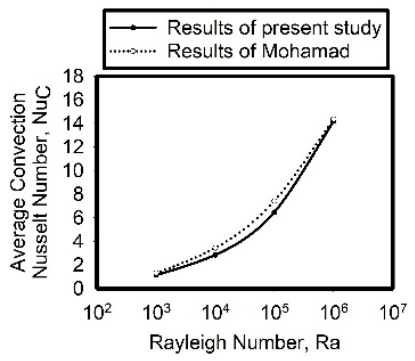

Fig. 4 Validation with Mohamad (1995).

\subsection{The different cases considered for the analysis}

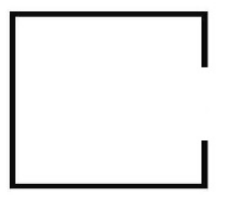

Case 1 Cavity with the right central port $(\mathrm{W} 1=\mathrm{W} 3)$

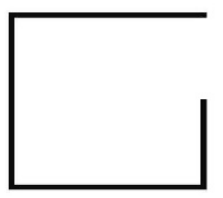

Case 3 Cavity with the right top port $(\mathrm{W} 3=0)$

Fig. 5 Openings in different cases considered for the present analysis.

For the optimization of cooling of left isothermal hot wall and finding the optimal opening in right side wall four geometries are considered and discussed as shown in Fig. 5. The cases 1,2 and 3 represent the location of port at middle, bottom and top of the right wall. In the case 4, the port is at an asymmetric position at the right wall. Here the subcases A, B, C and $\mathrm{D}$ of 1,2 and 3 has $25 \%, 50 \%, 75 \%$ and $100 \%$ openings respectively in the right side wall also shown in Table 6 . From the geometry of the problem in all cases, $\mathrm{W} 1+\mathrm{W} 2+\mathrm{W} 3=1.0$ Obviously the cases $1-\mathrm{D}, 2$ $\mathrm{D}$ and 3-D are same as they have $100 \%$ opening at the right side wall of the cavity.

Table 6 Geometrical dimensions of openings in different cases.

\begin{tabular}{|l|l|l|l|l|}
\hline \multicolumn{2}{|l|}{ Case } & $\begin{array}{l}\text { Size of Lower } \\
\text { Vent Wall, W1 }\end{array}$ & $\begin{array}{l}\text { Size of Middle } \\
\text { Port, W2 }\end{array}$ & $\begin{array}{l}\text { Size of Top } \\
\text { Vent Wall, W3 }\end{array}$ \\
\hline \multirow{4}{*}{1} & A & 0.375 & 0.250 & 0.375 \\
\cline { 2 - 5 } & B & 0.250 & 0.500 & 0.250 \\
\cline { 2 - 5 } & C & 0.125 & 0.750 & 0.125 \\
\cline { 2 - 5 } & D & 0 & 1.000 & 0 \\
\hline \multirow{5}{*}{2} & A & 0 & 0.250 & 0.750 \\
\cline { 2 - 5 } & B & 0 & 0.500 & 0.500 \\
\cline { 2 - 5 } & C & 0 & 0.750 & 0.250 \\
\cline { 2 - 5 } & D & 0 & 1.000 & 0 \\
\hline \multirow{3}{*}{3} & A & 0.750 & 0.250 & 0 \\
\cline { 2 - 5 } & B & 0.500 & 0.500 & 0 \\
\cline { 2 - 5 } & C & 0.250 & 0.750 & 0 \\
\cline { 2 - 5 } & D & 0 & 1.000 & 0 \\
\hline \multirow{3}{*}{4} & A & 0.250 & 0.250 & 0.500 \\
\cline { 2 - 5 } & B & 0.500 & 0.250 & 0.250 \\
\hline
\end{tabular}

\subsection{Typical results for the different geometries}

This section presents and discusses the typical results for the cases 1, 2, 3 and 4 . The physical significance of these results and there comparison is also presented.

\section{Streamlines and Isotherms}

This section presents the streamlines and isotherms for the cases 1, 2, 3 and 4 . These streamlines and isotherms in the different cases is discussed and compared.

\section{Streamlines and Isotherms for the case 1}

In this case the cavity has a central port i.e. a symmetrical opening at the center of right wall and $\mathrm{W} 1=\mathrm{W} 3=0.5(1.0-\mathrm{W} 2)$. The streamlines and isotherms for the four cases having $25 \%, 50 \%, 75 \%$ and $100 \%$ opening in the right side adiabatic wall is shown in Fig. 6. On observation it is found that there in the case $1-\mathrm{A}$ and $1-\mathrm{B}$ having $25 \%$ and $50 \%$ openings, the port size has a very small yet a significant influence on the streamlines. A small amount of fresh cold air enters in the cavity and a small amount of hot air leaves the cavity through these small openings.

There on close observation of streamlines and isotherms in the cavities near the opening, it is observed that there are three zones at the opening of cavity. At the first zone near the bottom of openings, some fresh cold air is found to be entering in the cavity. In the second zone at the middle of the opening there is no significant inflow or outflow of air and air is almost stagnant there. But in this narrow zone there is a steep temperature gradient and a number of isotherms can be seen emerging out from this zone. At the third zone near the top of openings, some hot air is leaving the cavity. The small size of opening restricts the sizes of all these three zones in the cases 1-A and 1-B. But the case 1-C and 1-D having $75 \%$ and $100 \%$ openings have a fully developed inflow and outflow of air through the openings. There in these cases greater number of streamlines cut the opening line. In these cases, the number of streamlines as well as the spacing between the streamlines near the opening is increased showing increased volume of air inflow and outflow. This results in better cooling of left isothermal hot wall which is manifested by the steep temperature gradient and increased convection Nusselt number at the left isothermal hot wall.

An important observation is the weak air circulations in the central part of cavity in all cases. But the central streamlines get bulged outwards with the increase in the size of opening. This shows that the air enters in 
the cavity along the bottom adiabatic wall, rises along the left isothermal hot wall and leaves the cavity along the top adiabatic wall. There with the increase in the size of opening the streamlines becomes denser near the left isothermal hot wall. This shows increased air velocity near the left isothermal hot wall with the increase in the size of opening.
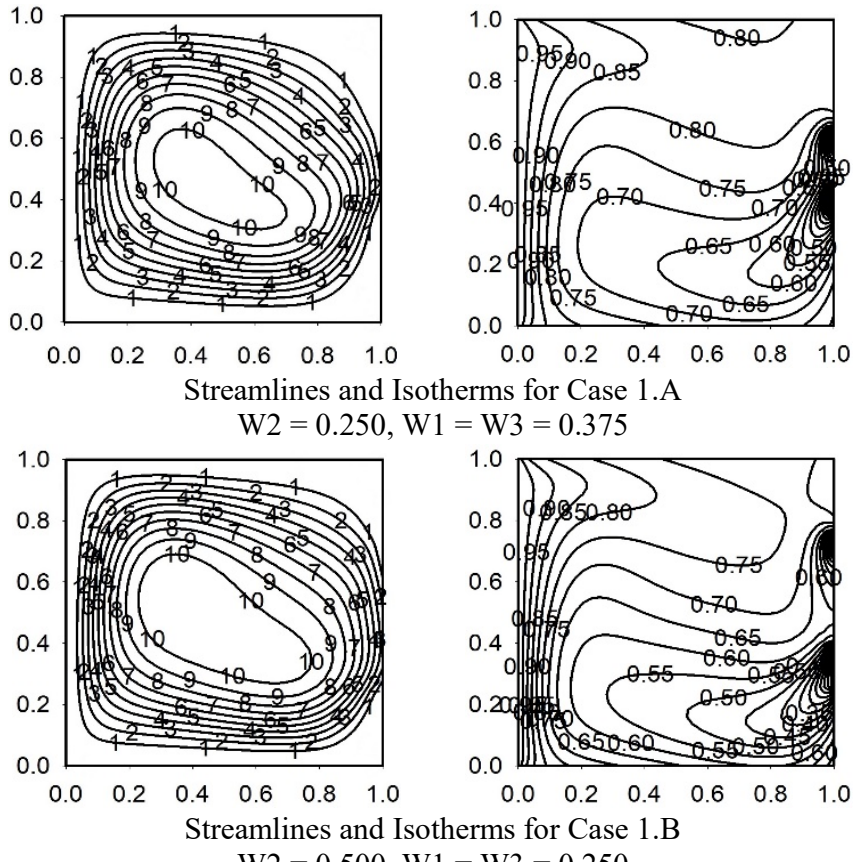

$\mathrm{W} 2=0.500, \mathrm{~W} 1=\mathrm{W} 3=0.250$

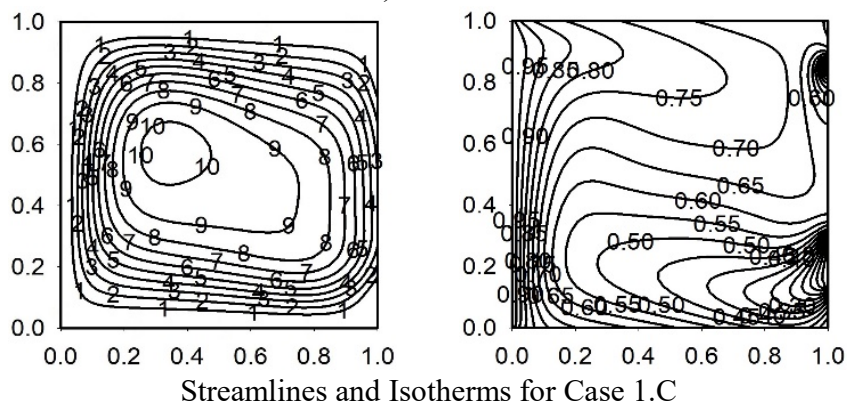
$\mathrm{W} 2=0.750, \mathrm{~W} 1=\mathrm{W} 3=0.125$

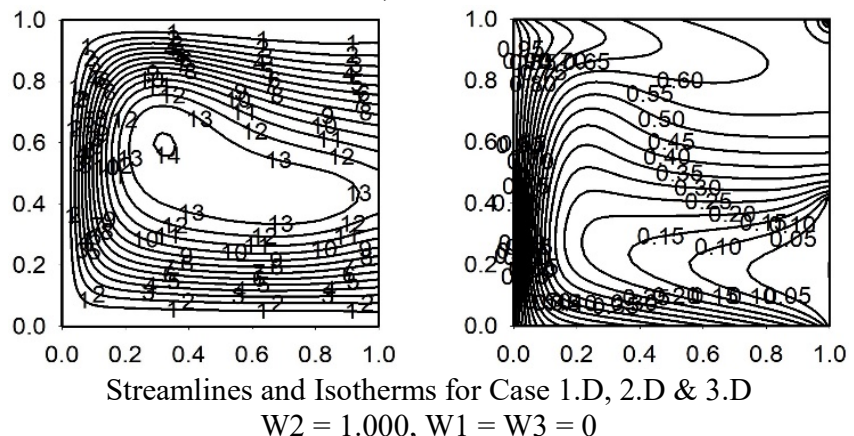

Fig. 6 Streamlines (left) and Isotherms (right) in Case $1 \mathrm{~W} 1=\mathrm{W} 3=$ $0.50(1.0-\mathrm{W} 2)$. For $\mathrm{A}=1, \mathrm{~N}_{\mathrm{rc}}=42.261, \mathrm{Pr}=0.70, \mathrm{Ra}_{\mathrm{H}}=$ $1.0 \times 10^{5}, \mathrm{~T}_{\mathrm{R}}=0.854, \varepsilon=0.85$.

Comparing the isotherms in the three cases, it is observed that the isotherms gets shifted towards the left isothermal hot wall with the increase in size of opening. With the increase in size of opening the temperature of upper half of cavity is significantly reduced. The radiative interaction between the walls of cavity also affects the isotherms in the cavity and the formation of a thermal boundary layer near the adiabatic walls is observed. Thus, it is inferred that the left isothermal hot wall loses heat to the all adiabatic walls through the radiative heat transfer. The incoming fresh intake of cold air picks some heat from the right bottom adiabatic wall and the bottom adiabatic wall. Then it picks some heat from the left isothermal hot wall also. Afterwards it interacts with the top adiabatic wall and right top adiabatic wall. Afterwards a portion of hot air escapes from the right opening of the cavity and the remaining portion of hot air mixes with incoming fresh intake of cold air. This phenomenon is well supported by the streamlines, isotherms, horizontal air velocity at the opening, temperature and velocity at the different sections inside the cavity.

\section{Streamlines and Isotherms for the case 2}
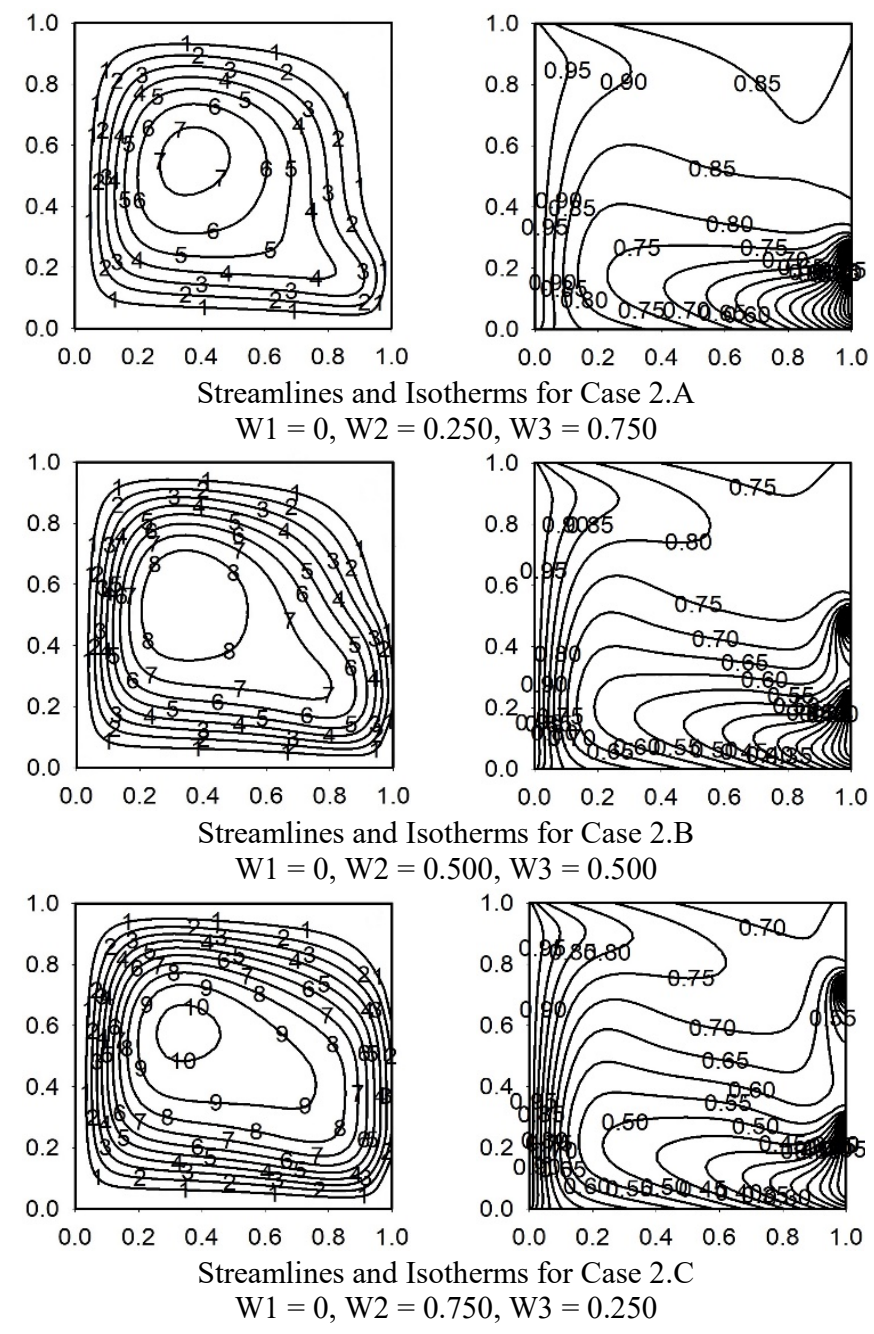

Fig. 7 Streamlines (left) and Isotherms (right) in Case $2 \mathrm{~W} 1=0$, $\mathrm{W} 3=1.0-\mathrm{W} 2$. For $\mathrm{A}=1, \mathrm{~N}_{\mathrm{rc}}=42.261, \mathrm{Pr}=0.70, \mathrm{RaH}=$ $1.0 \times 10^{5}, \mathrm{~T}_{\mathrm{R}}=0.854, \varepsilon=0.85$.

In the present study, the analysis is made for the different port sizes and vent wall sizes. For the completeness of the present analysis and optimization of cooling, the analysis is made for the different positioning of ports. The size of port and its positioning affects the air circulation and cooling within the cavity differently. In this case, analysis is made when the port is at the bottom of the right side adiabatic wall. The subcases discussed in this case have $25 \%, 50 \%, 75 \%$ and $100 \%$ openings. It is to be noted that the case $2-\mathrm{D}$ having $100 \%$ opening in the right side adiabatic wall is same as the case 1-D.

In this case, the fresh intake of cold air enters in the cavity from the lower portion of opening in the right side adiabatic wall of the cavity. Similar to the previous cases the hot air leaves from the upper part of the opening. But in this case the hot air sweeps more volume of the cavity 
and the upper half and left-bottom quarter of the cavity is filled with the hot air. It is well indicated by the isotherms and streamlines in Fig. 7 and further confirmed by the other plots of these cases.

Thus, in this case, there is a poor cooling within the cavity and most of the hot air is recirculated in the cases having a small opening in the right side adiabatic wall. The small opening at the bottom causes stagnation at the top right corner of the cavity observed through the streamlines in case 2-A and 2-B. These streamlines reveal that there is weak circulation of air in the central part of the cavity.

Isotherms are rarer and spread away from the left isothermal hot wall of the cavity. This shows the poor cooling of left isothermal hot wall and the cavity is filled with hot air. However, a small amount of fresh ambient air entering in the cavity reduces the temperature near the bottom wall of the cavity.

\section{Streamlines and Isotherms for the case 3}
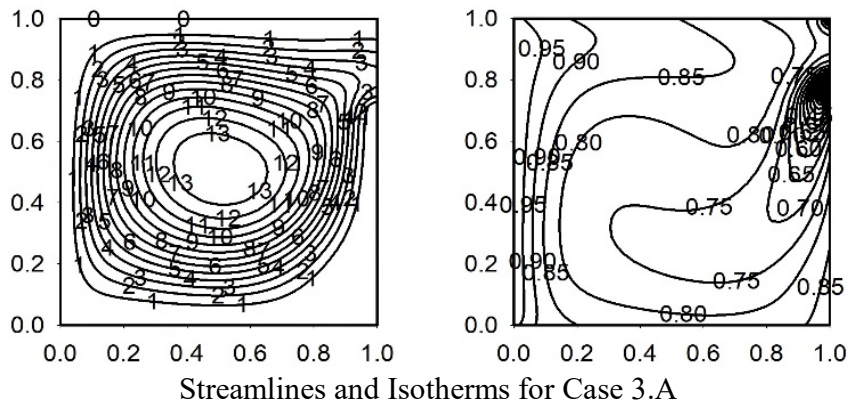

$\mathrm{W} 1=0.750, \mathrm{~W} 2=0.250, \mathrm{~W} 3=0$
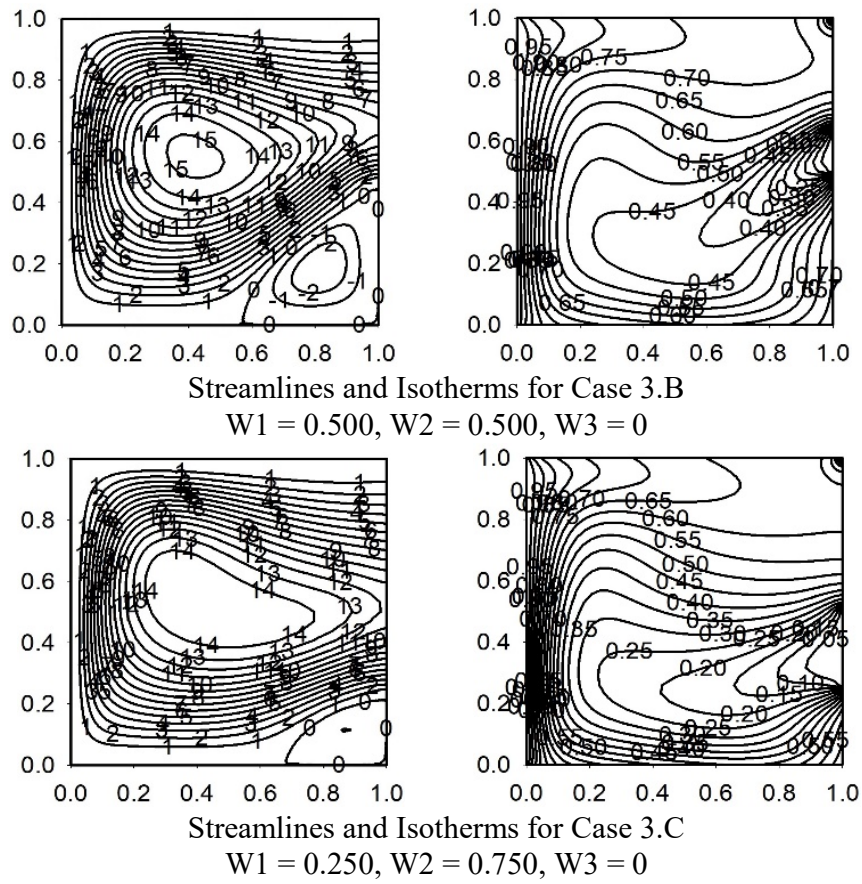

Fig. 8 Streamlines (left) and Isotherms (right) in Case $3 \mathrm{~W} 3=0$, $\mathrm{W} 1=1.0-\mathrm{W} 2$. For $\mathrm{A}=1, \mathrm{~N}_{\mathrm{rc}}=42.261, \mathrm{Pr}=0.70, \mathrm{Ra}_{\mathrm{H}}=$ $1.0 \times 10^{5}, \mathrm{~T}_{\mathrm{R}}=0.854, \varepsilon=0.85$.

In continuation of the present study, there is an important case in which the port is located at the top of the right side adiabatic wall. This is an interesting case as the denser smooth streamlines are observed in this case as shown in Fig. 8. The denser smooth streamlines represent greater volume of air flow and higher air velocity.

In this case, the rising hot air along the left isothermal hot wall moves towards right along the top wall and escapes out through the port. The outgoing hot air stream and incoming fresh cold air stream are well separated in this case. The outgoing air stream is straight and almost perpendicular to the exit port as there is no obstruction to the outgoing air stream.

The isotherms for this case shown in Fig. 8 reveal that the lower portion of the cavity has smaller temperature due to incoming fresh air at ambient temperature. There is a rapid decrease in the temperature of the major part of the cavity with the increase in port size of the right adiabatic wall. There are fewer air recirculation currents resulting in effective and better cooling of the left isothermal hot wall.

But there a secondary air circulation is observed at right bottom corner of the cavity. Near this zone the wall of cavity gets heated due to radiation. But there a poorer cooling is observed due to secondary air circulation loops.

In comparison with the cases 1 and 2, the streamlines and isotherms in the case 3 reveals the improved air circulation and resulting effective cooling of the left isothermal hot wall. This also shows the effective cooling of other surfaces within the cavity due to strong air circulation currents formed.

\section{Streamlines and Isotherms for the case 4}

In this case, the cavity has an eccentric port i.e. an asymmetrical opening near the center of the right wall. The asymmetrical opening or port is $25 \%$ of right side wall for the two cases. For the first case the opening is near the bottom wall and in second case the opening is near the top wall. The streamlines and isotherms for the two cases shown in Fig. 9 reveal that for the second case streamlines are denser. This shows that air circulation is higher for the case 4-B. The isotherms reveal the better cooling of cavity in the case 4-B.

In case 4-A, there is a zone with a weak air circulation at top right corner inside the cavity. But in the case $4-\mathrm{B}$, the size of this weak air circulation zone is significantly reduced. There in the case 4-A, there is a weak secondary air circulation is observed at the top right corner of the cavity. This small region of secondary air circulation is significantly reduced for the case $2-\mathrm{B}$.
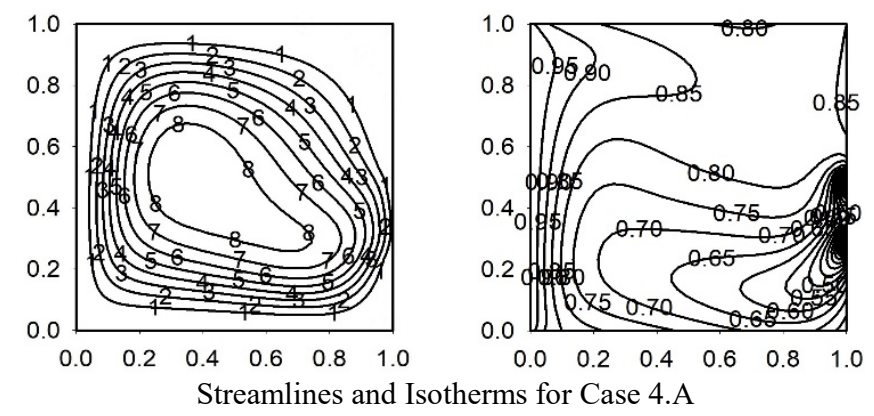

Streamlines and Isotherms for Case 4.A $\mathrm{W} 1=\mathrm{W} 2=0.250, \mathrm{~W} 3=0.500$

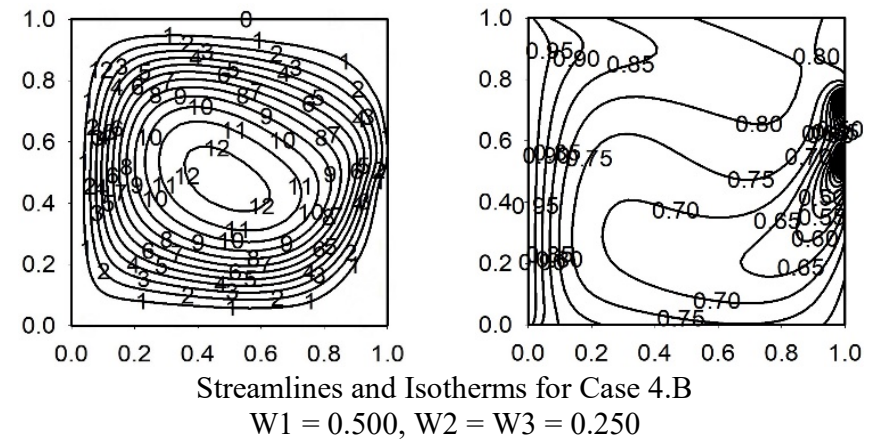

Fig. 9 Streamlines (left) and Isotherms (right) in Case $4 \mathrm{~W} 1 \neq \mathrm{W} 3$. For $\mathrm{A}=1, \mathrm{~N}_{\mathrm{rc}}=42.261, \mathrm{Pr}=0.70, \mathrm{Ra}_{\mathrm{H}}=1.0 \times 10^{5}, \mathrm{~T}_{\mathrm{R}}=0.854$, $\varepsilon=0.85$.

\section{The Horizontal Air Velocity at the Exit Port}

The non-dimensional horizontal air velocity at the exit port of the cavity for the all four cases is shown in Fig. 10. It is observed that the horizontal 
air velocity increases with the increase in port sizes in the case 1,2 and 3. In case 4-A and 4-B, the port sizes are same for the two cases. But the horizontal air velocity is higher for the case $4-\mathrm{B}$, where the port is near to the top adiabatic wall.

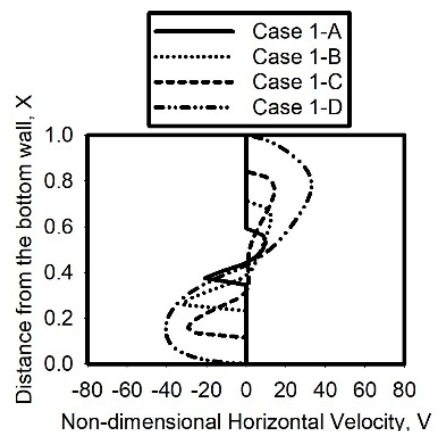

Case 1

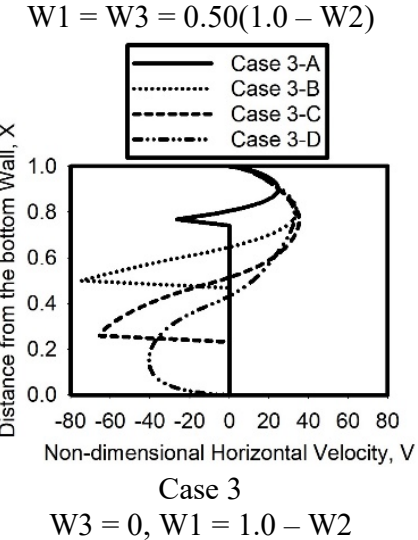

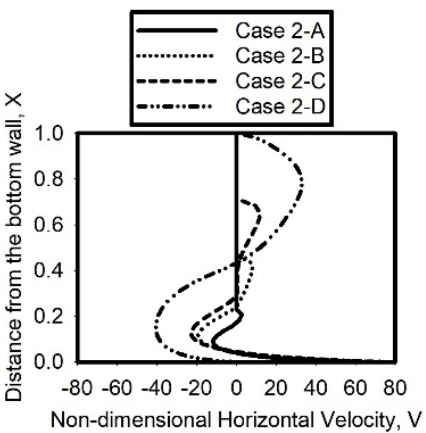

Case 2

$\mathrm{W} 1=0, \mathrm{~W} 3=1.0-\mathrm{W} 2$

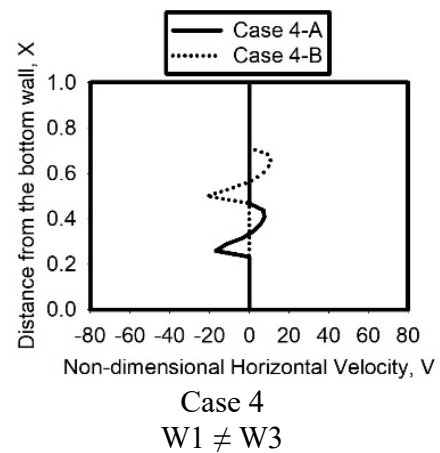

Fig. 10 The horizontal air velocity at the exit port in different cases. For $\mathrm{A}=1, \mathrm{~N}_{\mathrm{rc}}=42.261, \mathrm{Pr}=0.70, \mathrm{RaH}=1.0 \times 10^{5}, \mathrm{~T}_{\mathrm{R}}=0.854$, $\varepsilon=0.85$.

In the cases 1, 2 and 4 discussed the hot air rises along the left isothermal hot wall and moves towards right along the top wall. The presence of the top right vent wall acts as an obstruction producing hydrodynamic resistance on the hot air stream moving it in the downward direction. This results that a part of hot air stream is recirculated along with the incoming fresh ambient air.

In the case 3, the absence of the top right vent wall results in smooth escaping of hot air from the cavity without recirculation, which is replaced by the fresh air at ambient temperature. The high nondimensional horizontal air velocity is observed in this case. The highest average exit velocity of hot air is observed in the case with the right side completely open.

The ambient air enters in the cavity from the bottom part of the port at the right side adiabatic wall. It replaces the hot air escaped through the upper part of the port. Therefore, the high velocity of incoming air at the port is observed in the cases where the outgoing air velocity is higher.

In all the cases near the middle of the port or opening in the right side adiabatic wall, there is a region at which the non-dimensional horizontal air velocity is close to zero. This resembles that there is a virtual partition at the middle of the right side port or opening dividing it into two parts, the bottom one for incoming fresh ambient air and the top one for the outgoing hot air.

\section{Local Nuc at Left Isothermal Hot Wall}

The local $\mathrm{Nu}_{\mathrm{C}}$ at the left isothermal hot wall for the three cases is shown in Fig. 11. It is observed that the local $\mathrm{Nu}_{\mathrm{C}}$ is maximum at a point near the bottom. It is the point where the incoming fresh ambient air starts interacting with the left isothermal hot wall. The incoming fresh air stream moves in upward direction along the left isothermal hot wall. It gradually picks some heat from the left isothermal hot wall by interacting with it. There is a gradual decrease in temperature difference between the left isothermal hot wall and the interacting air. This causes decrease in the local $\mathrm{Nu}_{\mathrm{C}}$ at the left wall.
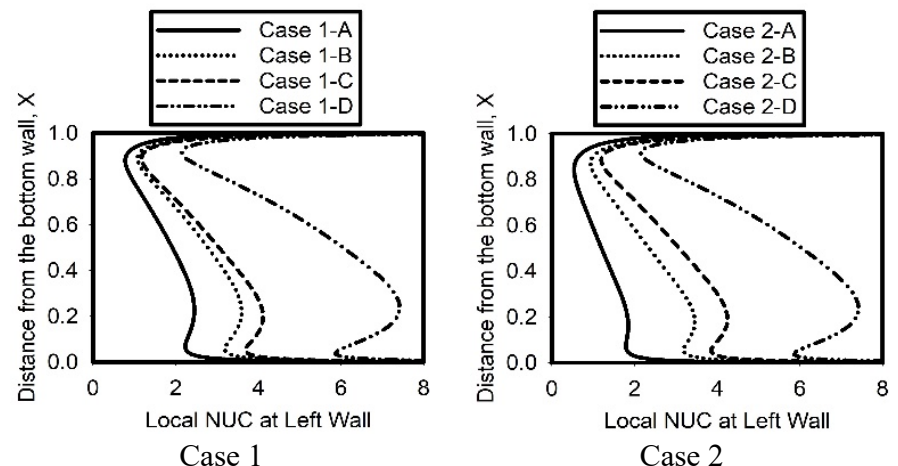

$\mathrm{W} 1=\mathrm{W} 3=0.50(1.0-\mathrm{W} 2)$

Case 2

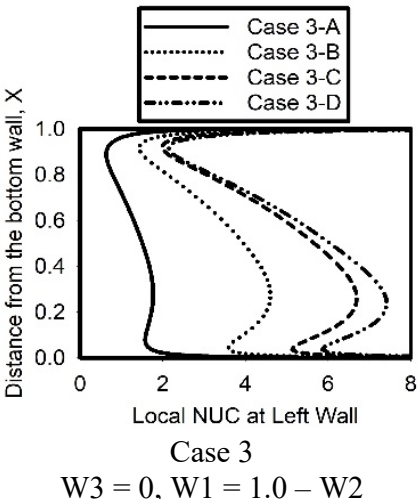

Fig. 11 Local Convection Nusselt Number (NUC) at Left Wall in different cases. For $\mathrm{A}=1, \mathrm{~N}_{\mathrm{rc}}=42.261, \mathrm{Pr}=0.70$, $\mathrm{RaH}=$ $1.0 \times 10^{5}, \mathrm{~T}_{\mathrm{R}}=0.854, \varepsilon=0.85$.

The air circulation in the cavity increases with the increase in dimension of the port or the opening in the right side adiabatic wall. This increases the cooling of the left isothermal hot wall. From these three graphs, it is observed that local $\mathrm{Nu}_{\mathrm{C}}$ and $\overline{\mathrm{Nu}_{\mathrm{C}}}$ at the left isothermal hot wall increases with the increase in the port sizes. The effect of increasing the port size on local $\mathrm{Nuc}$ at the left isothermal hot wall is observed in all the cases, but it is the most significant in case 3 having the port at the top of right adiabatic wall.

The position of opening or port is different in all these three cases. The effect of variation of port sizes in each case is studied and analyzed. There is a change in flow pattern or streamlines in each case with the variation in positioning of port and port sizes. The circulation of air is lesser at the left top and bottom corner of the cavity. The interaction of primary air stream with the points near the top and bottom of left isothermal hot wall is lesser in comparison with the other parts of the wall. This results in a local minimum of local $\mathrm{Nuc}$ at these points. These points have the lower local $\mathrm{Nuc}$ in comparison with the other points in the close vicinity. However, the local $\mathrm{Nu}_{\mathrm{C}}$ at the extreme ends of left isothermal hot wall is large due to the interaction of left isothermal hot wall with the adiabatic walls near it.

\section{Local NuR at Left Isothermal Hot Wall}

The local $\mathrm{Nu}_{\mathrm{R}}$ at left isothermal hot wall for the three cases is shown in Fig. 12. It is observed that the local NuR is minimum at the bottom and top, whereas it is maximum at the middle part of left isothermal hot wall. The middle part of left wall is away from the other walls of the cavity. The middle part of the left isothermal hot wall is near the front of the port at the right adiabatic wall allowing more thermal radiations from the left isothermal hot wall to escape out of the cavity. These are the few reasons 
attributed for the maximum local $\mathrm{Nu}_{\mathrm{R}}$ near the middle part of the left isothermal hot wall.

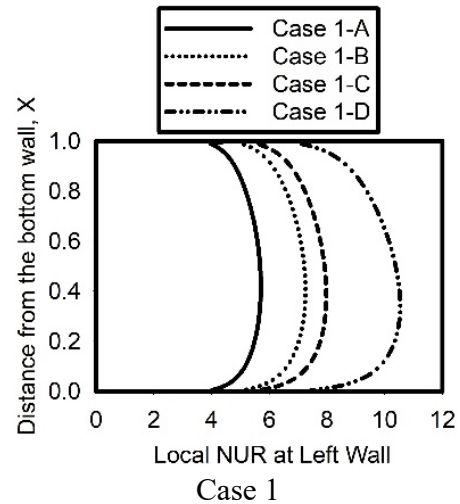

Case 1

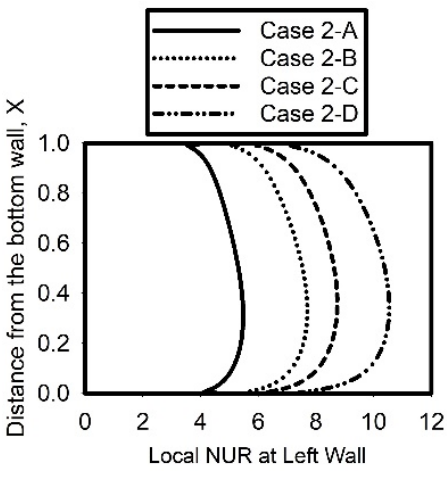

Case 2

$$
\mathrm{W} 1=\mathrm{W} 3=0.50(1.0-\mathrm{W} 2)
$$

$\mathrm{W} 1=0, \mathrm{~W} 3=1.0-\mathrm{W} 2$

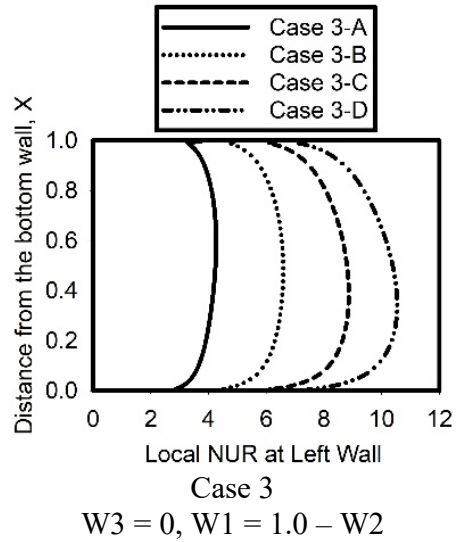

Fig. 12 Local Radiation Nusselt Number (NUR) at Left Wall in different cases. For $\mathrm{A}=1, \mathrm{~N}_{\mathrm{rc}}=42.261, \mathrm{Pr}=0.70, \mathrm{Ra}_{\mathrm{H}}=$ $1.0 \times 10^{5}, \mathrm{~T}_{\mathrm{R}}=0.854, \varepsilon=0.85$.

It is also observed that increasing the port size increases the local $\mathrm{Nu}_{\mathrm{R}}$ and $\overline{\mathrm{Nu}_{\mathrm{R}}}$ at left wall significantly. The presence of port in front of left wall results an increase in the radiant energy leaving the left wall. The presence of port or opening at the right adiabatic wall decreases the dimensions of the solid adiabatic walls at the right. Thus a lesser irradiation is received at the left wall from the front right adiabatic walls.

Comparing the three cases it is observed that the local $\mathrm{Nu}_{\mathrm{R}}$ for small openings (for $\mathrm{W} 2=0.250$ and 0.500 ) is lower in case 3 than in the case 1 and 2. This may be attributed to the presence of large right bottom adiabatic vent wall $(\mathrm{W} 1=0.750$ and 0.500$)$ in the case 3 and increased cooling of left isothermal hot wall by natural convection. Improved cooling of left wall by natural convection due to increased air circulation inside the cavity is one of the other attributing factors.

\section{Non-dimensional Bottom Wall Temperature}

The non-dimensional bottom wall temperature for the three cases at different port sizes is shown in Fig. 13. The adiabatic bottom wall gains heat from other walls through radiative heat transfer and loses heat by convective and radiative heat transfer. It loses heat to the other walls also by radiative heat transfer. The incoming fresh ambient air rises along the left isothermal hot wall after picking some heat from the right bottom vent wall and the bottom wall. It is observed that the left of bottom adiabatic wall has non-dimensional temperature close to unity due to left isothermal hot wall. The temperature of bottom wall decreases from left to right up to $\mathrm{Y}=0.8$ approximately in all the cases. In the cases where the right bottom vent wall is present $(\mathrm{W} 1 \neq 0)$, the temperature of bottom wall increases close to it. This is due to radiative heat transfer between the bottom adiabatic wall and the right bottom adiabatic vent wall. In the absence of the right bottom vent wall $(\mathrm{W} 1=0)$, the temperature of right end of bottom wall is close to the ambient temperature due to incoming fresh ambient air.
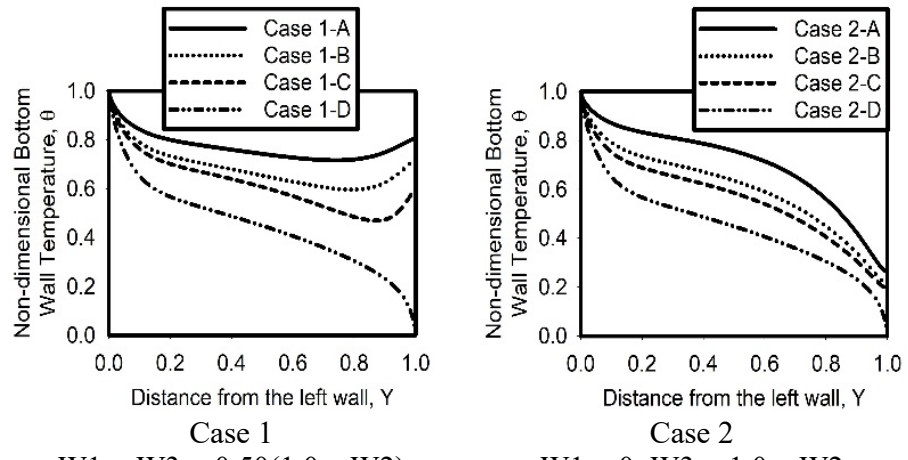

$\mathrm{W} 1=\mathrm{W} 3=0.50(1.0-\mathrm{W} 2)$

Case 2

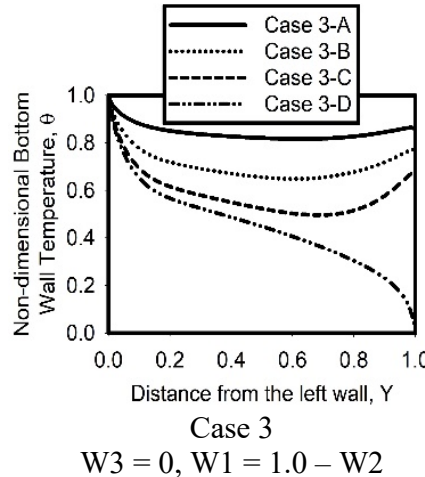

Fig. 13 Non-dimensional Bottom Wall Temperature in different cases. For $\mathrm{A}=1, \mathrm{~N}_{\mathrm{rc}}=42.261, \mathrm{Pr}=0.70, \mathrm{Ra}_{\mathrm{H}}=1.0 \times 10^{5}, \mathrm{~T}_{\mathrm{R}}=0.854$, $\varepsilon=0.85$.

\section{Non-dimensional Top Wall Temperature}
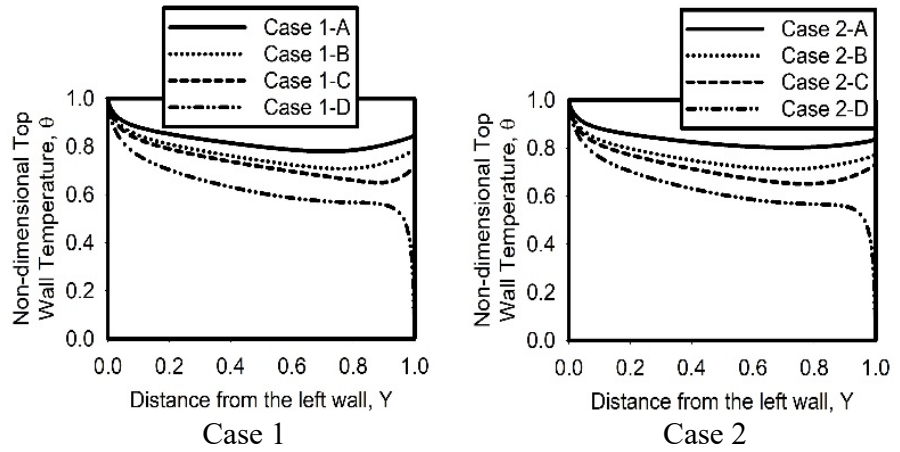

$\mathrm{W} 1=\mathrm{W} 3=0.50(1.0-\mathrm{W} 2)$

Case 2

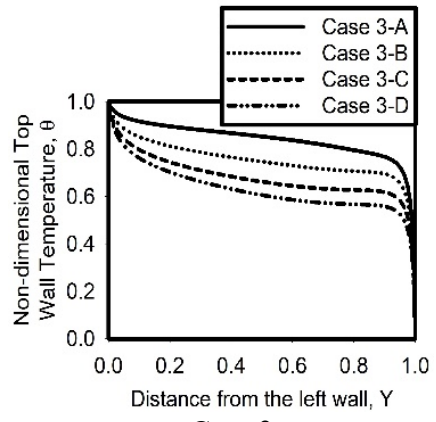

Case 3

$\mathrm{W} 3=0, \mathrm{~W} 1=1.0-\mathrm{W} 2$

Fig. 14 Non-dimensional Top Wall Temperature in different cases. For $\mathrm{A}=1, \mathrm{~N}_{\mathrm{rc}}=42.261, \mathrm{Pr}=0.70, \mathrm{Ra}_{\mathrm{H}}=1.0 \times 10^{5}, \mathrm{~T}_{\mathrm{R}}=0.854$, $\varepsilon=0.85$. 
The non-dimensional top wall temperature for the three cases at the different port sizes is shown in Fig. 14. The adiabatic top wall gains heat from other walls through radiative heat transfer and the hot air passing over it. The incoming fresh ambient air rises along the left wall after picking some heat from the right bottom vent wall and bottom wall. It interacts with the top wall and right top vent wall before exiting out of the cavity. It is observed that the left of top adiabatic wall has nondimensional temperature close to unity due to left isothermal hot wall. The temperature of top wall decreases from left to right up to $\mathrm{Y}=0.8$ approximately in all the cases. In the cases where right top vent wall is present $(\mathrm{W} 3 \neq 0)$, the temperature of top wall increases near the right top vent wall. This is due to radiative heat transfer between the top adiabatic wall and right top adiabatic vent wall. In absence of the right top vent wall (W3 = 0$)$, the temperature of top wall decreases continuously from left to right.

\section{Non-dimensional Temperature at different vertical section for case 1}

The non-dimensional temperature at the different vertical sections of the cavity (at $\mathrm{Y}=0.250,0.500$ and 0.750 ) for the case 1 for different port sizes is shown in Fig. 15. These sections are parallel to the left isothermal hot wall and temperature variation at these sections are plotted for analyzing the effect of distance from the left wall inside the cavity. The temperature of bulk of cavity is very high if the size of port is very small. The other cases of present study can show the similar interesting results, which are not included in present study to avoid the repetition of similar analysis. However, the isotherms in the different cases discussed earlier reveal the complete picture of temperature of bulk volume inside the cavity in these cases.

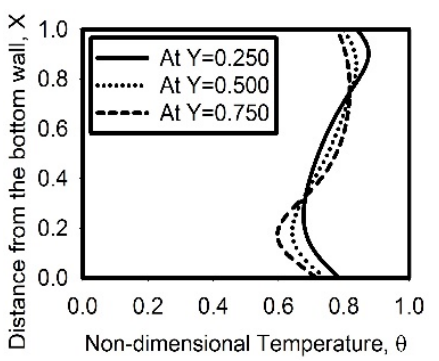

Case $1-\mathrm{A}(\mathrm{W} 1=0.375, \mathrm{~W} 2=$ $0.250, \mathrm{~W} 3=0.375)$

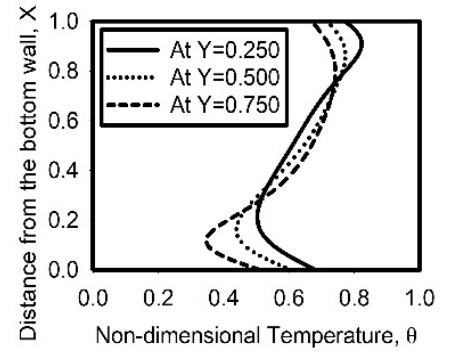

Case 1-C

$(\mathrm{W} 1=0.125, \mathrm{~W} 2=0.750, \mathrm{~W} 3=0.125)$

Fig. 15 Non-dimensional Temperature at different vertical section of cavity in case 1 . For $\mathrm{A}=1, \mathrm{~N}_{\mathrm{rc}}=42.261, \mathrm{Pr}=0.70, \mathrm{Ra}_{\mathrm{H}}=$ $1.0 \times 10^{5}, \mathrm{~T}_{\mathrm{R}}=0.854, \varepsilon=0.85$.

It is observed that with the increase in the port size, the temperature near the bottom wall of cavity decreases. This agrees with the expected results as more air at ambient temperature rushes inside the cavity towards the bottom wall with the increase in the dimension of port. The temperature near the top is higher due to the hot adiabatic top wall. The increase in port size has a less significant effect on temperature near the left wall and in the region of cavity near it. The temperature at the middle section of the cavity has some variation in temperature due to air circulations inside the cavity. The temperature variation at the vertical section close to the right end shows higher temperature at top and bottom due to the presence of right top and bottom vent walls, whereas it has some variations due to the incoming fresh ambient air at the bottom part of right port and outgoing hot air at the top part of right port.

\section{Non-dimensional Vertical Velocity $U$ at different horizontal section for case 1}

The non-dimensional vertical velocity of air at the two different horizontal cross sections of the cavity (at $\mathrm{X}=\mathrm{W} 1$ and $\mathrm{X}=\mathrm{W} 1+\mathrm{W} 2$ ) at different port sizes for the case 1 is shown in Fig. 16. These cross sections are horizontal and non-dimensional vertical velocity of air at these sections are plotted for analyzing the air streams moving upwards inside the cavity. The non-dimensional vertical velocity of air near the left isothermal hot wall is upward and significantly high. The nondimensional vertical velocity near the right vent wall is downwards.

The non-dimensional vertical velocity of air reveals the effect of buoyant forces inside the cavity. But it does not represent the complete picture of the air streams inside the cavity. The streamlines show that horizontal component of air velocity at incoming and outgoing air stream as well as at the air stream near the top and bottom of the cavity is significant. These streamlines show the complete picture of air circulation inside the cavity. The dimensions of port affect the profile of non-dimensional vertical velocity of air inside the cavity and it is more significant near the left and right part of the cavity. The other cases of present study can also reveal the similar interesting results, which are not included in present study to avoid the repetition of similar analysis. However, the streamlines in different cases reveal the complete picture of air circulation in the bulk volume of the cavity in these cases.

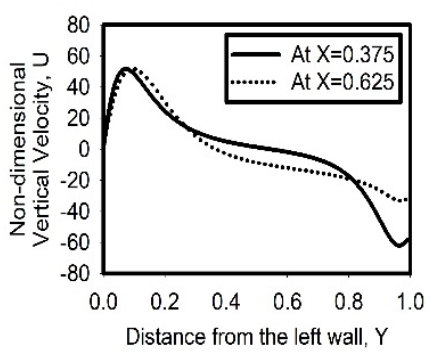

Case $1-\mathrm{A}(\mathrm{W} 1=0.375, \mathrm{~W} 2=$ $0.250, \mathrm{~W} 3=0.375)$

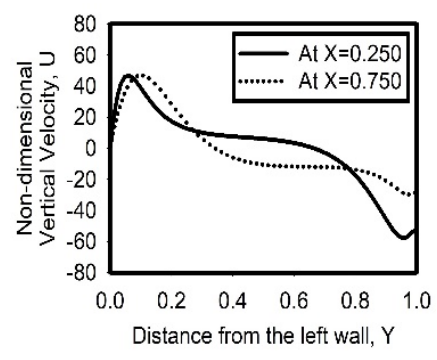

Case $1-\mathrm{B}(\mathrm{W} 1=0.250, \mathrm{~W} 2=$ $0.500, \mathrm{~W} 3=0.250)$

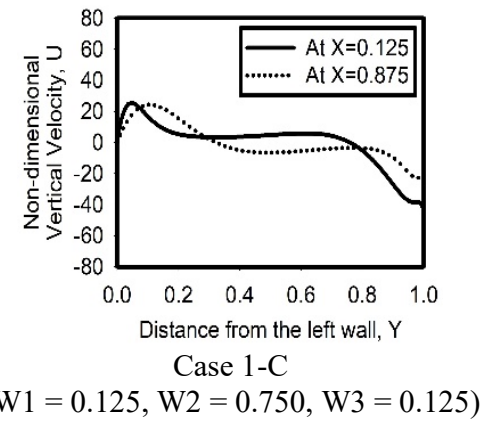

Fig. 16 Non-dimensional Vertical Velocity (U) at different horizontal section in case 1 . For $\mathrm{A}=1, \mathrm{~N}_{\mathrm{rc}}=42.261, \mathrm{Pr}=0.70, \mathrm{Ra}_{\mathrm{H}}=$ $1.0 \times 10^{5}, \mathrm{~T}_{\mathrm{R}}=0.854, \varepsilon=0.85$.

\section{Variation of $\overline{\mathrm{Nu}_{\mathrm{C}}}$ at Left Isothermal Hot Wall in different cases with different sizes of opening}

The Fig. 17 shows the variation of $\overline{\mathrm{Nu}_{\mathrm{C}}}$ at the left wall for the different port sizes in three cases. These plots reveal that the $\overline{\mathrm{Nu}_{\mathrm{C}}}$ at left wall increases with the port size. With the increase in port size, the air circulation inside the cavity is increased, but the size of the right vent wall is decreased. These factors affect the streamlines in the cavity and 
cooling of the left isothermal hot wall differently. The following plot reveals that with the different small port ratios $(\mathrm{W} 2 \leq 0.50)$, the $\overline{\mathrm{Nu}_{\mathrm{C}}}$ at the left wall is almost the same in the three cases. But in the case 3, with the large port ratios $(\mathrm{W} 2 \geq 0.50)$, the $\overline{\mathrm{Nu}_{\mathrm{C}}}$ at the left wall is significantly higher. At the port ratio $\mathrm{W} 2=0$ and 1.0 in all these three cases, these cavity has the same geometry and therefore all these three plots coincide at these points.

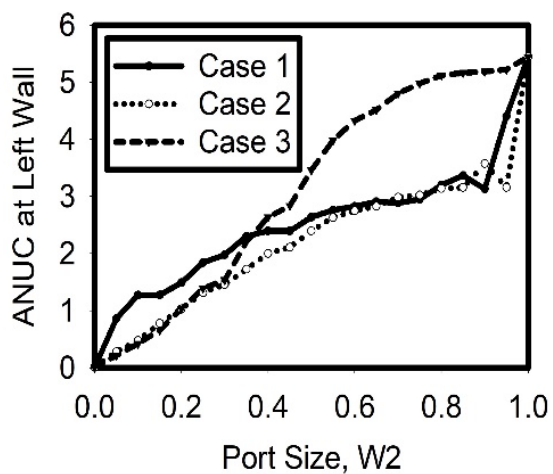

Fig. 17 Variation of $\overline{\mathrm{Nu}_{\mathrm{C}}}$ (ANUC) at Left Wall in different cases with different opening sizes. For $\mathrm{A}=1, \mathrm{~N}_{\mathrm{rc}}=42.261, \operatorname{Pr}=$ $0.70, \mathrm{Ra}_{\mathrm{H}}=1.0 \times 10^{5}, \mathrm{~T}_{\mathrm{R}}=0.854, \varepsilon=0.85$.

Variation of $\overline{\mathrm{Nu}_{\mathrm{R}}}$ at Left Isothermal Hot Wall in different cases with different sizes of opening

The Fig. 18 shows the variation of $\overline{\mathrm{Nu}_{\mathrm{R}}}$ at the left wall for the different port sizes in three cases. These plots reveal that the $\overline{\mathrm{Nu}_{\mathrm{R}}}$ at left wall increases with the port size. The presence of open port in front of left isothermal hot wall causes more thermal radiations to escape out of the cavity. As no radiation is reflected back by a port, the presence of a port or opening in a wall of cavity can be compared with a blackbody on the wall. The following plots reveal that the $\overline{\mathrm{Nu}_{\mathrm{R}}}$ increases with the dimension of port on right side, while the position of port has a less significant effect on it. It is further revealed that for the smaller port ratios (W2 $\leq 0.60$ ) the case 1 has better radiative cooling of left wall, whereas for the larger port ratios (W2 $\geq 0.60$ ) the case 3 has better radiative cooling. At the port ratio $\mathrm{W} 2=0$ and 1.0, in all these three cases, the cavity has the same geometry and therefore all these three plots coincide at these points.

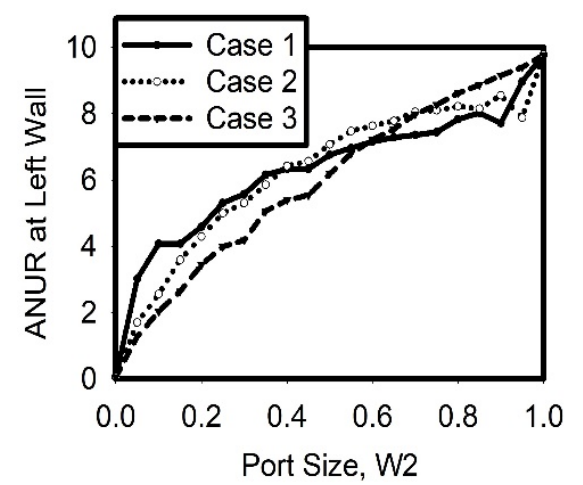

Fig. 18 Variation of $\overline{\mathrm{Nu}_{\mathrm{R}}}$ (ANUR) at Left Wall in different cases with different opening sizes. For $\mathrm{A}=1, \mathrm{~N}_{\mathrm{rc}}=42.261, \mathrm{Pr}=$ $0.70, \mathrm{RaH}=1.0 \times 10^{5}, \mathrm{~T}_{\mathrm{R}}=0.854, \varepsilon=0.85$.

\section{Variation of $\overline{\mathrm{Nu}_{\mathrm{C}}}$ at Left Isothermal Hot Wall with Emissivity}

In the present problem, the left isothermal hot wall of cavity is cooled by the natural convection and surface radiation. The natural convection depends on the air circulation inside the cavity. The emissivity of the cavity walls affects the cooling of left wall as well as heating of the bottom, top and right adiabatic walls through radiative heat transfer. The heating of the adiabatic walls has a significant effect on the air circulation inside the cavity. Thus, the emissivity of wall affects the cooling of left wall by natural convection also. The emissivity of all the walls of the cavity is considered to be the same. The Fig. 19 shows the variation of $\overline{\mathrm{Nu}_{\mathrm{C}}}$ with emissivity of wall in the case 3 . The $\overline{\mathrm{Nu}_{\mathrm{C}}}$ at the left isothermal hot wall decreases with the increase in emissivity of the walls. This shows that emissivity of the walls affect the cooling of hot walls by both of the natural convection and surface radiation significantly. This is an important observation for the optimization of cooling inside the cavity by natural convection.

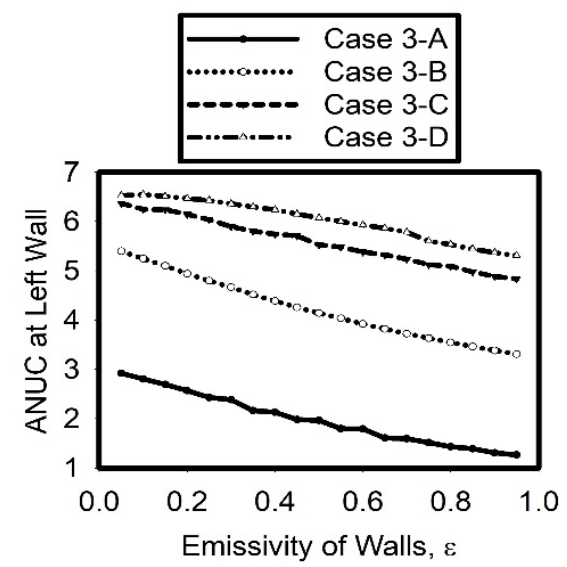

Fig. 19 Variation of $\overline{\mathrm{Nu}_{\mathrm{C}}}$ (ANUC) at Left Wall in different cases with Emissivity. For $\mathrm{A}=1, \mathrm{~N}_{\mathrm{rc}}=42.261, \mathrm{Pr}=0.70$, $\mathrm{RaH}=1.0 \times 10^{5}, \mathrm{~T}_{\mathrm{R}}=0.854$.

\section{Variation of $\overline{\mathrm{Nu}_{\mathrm{R}}}$ at Left Isothermal Hot Wall with} Emissivity

The Fig. 20 shows the variation of $\overline{\mathrm{Nu}_{\mathrm{R}}}$ at the left isothermal hot wall with emissivity of the walls in case 3 . The emissivity of all the walls of the cavity is considered to be the same. At the lower emissivity, the $\overline{\mathrm{Nu}_{\mathrm{R}}}$ at left wall is close to zero for all these three cases. It is inferred that at the lower emissivity, the radiative heat transfer between the walls is negligible for all the positions and dimensions of port or opening in all the cases. This plot reveals that the $\overline{\mathrm{Nu}_{\mathrm{R}}}$ at left isothermal hot wall increases with the emissivity of walls. The plots are almost linear and for the larger size of port or opening, the slope of the plot is higher. It is observed that for the larger dimensions of port or opening, the $\overline{\mathrm{Nu}_{\mathrm{R}}}$ at left isothermal hot wall is larger. At the higher emissivity, the radiative heat transfer is comparable to the convective heat transfer.

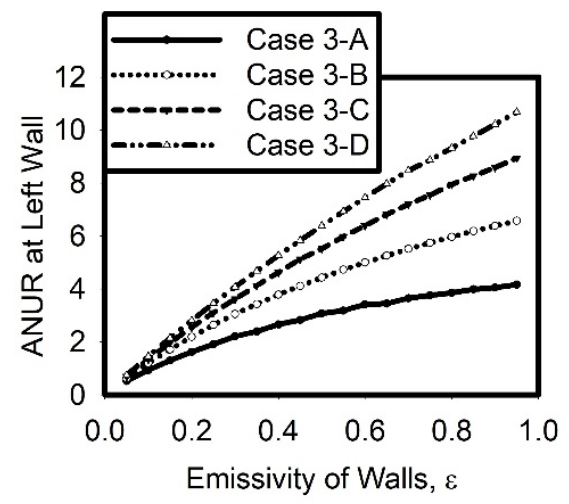

Fig. 20 Variation of $\overline{\mathrm{Nu}_{\mathrm{R}}}$ (ANUR) at Left Wall in different cases with Emissivity. For $\mathrm{A}=1, \mathrm{~N}_{\mathrm{rc}}=42.261, \mathrm{Pr}=0.7, \mathrm{Ra}_{\mathrm{H}}=$ $1.0 \times 10^{5}, \mathrm{~T}_{\mathrm{R}}=0.854$. 


\section{CORRELATIONS}

This section presents the correlations for $\overline{\mathrm{Nu}_{\mathrm{C}}}$ and $\overline{\mathrm{Nu}_{R}}$ for the cases 1 , 2 and 3 . The correlations and their physical significance in the present problem is discussed and explained.

\subsection{Correlations for $\overline{\mathrm{Nu}_{\mathrm{C}}}$ in Cases 1,2 and 3}

\section{Correlation for $\overline{\mathrm{Nu}_{\mathrm{C}}}$ in Case 1}

Based on a large set of data (approximately data 120 sets) a correlation for the $\overline{\mathrm{Nu}_{\mathrm{C}}}$ has derived as Eq. (13).

$\overline{N u_{C}}=0.3357 G r_{H}^{0.169}\left[\frac{N_{r c}}{N_{r c}+1}\right]^{-0.3660}(1+\varepsilon)^{-0.7073}(1+W)^{1.1925}$

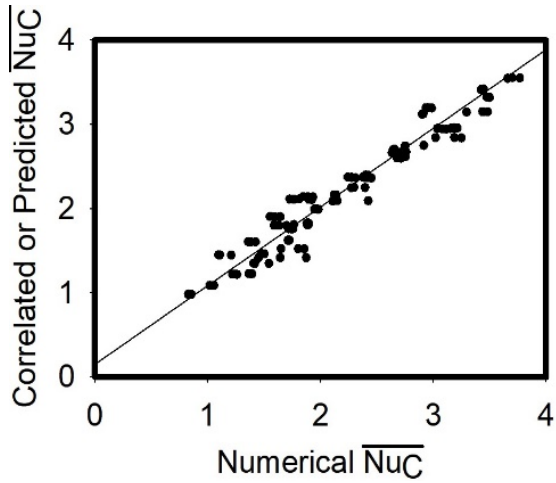

Fig. 21 Parity plot showing the goodness of fit for $\overline{\mathrm{Nu}_{\mathrm{C}}}$. Correlated $\overline{\mathrm{Nu}_{\mathrm{C}}}$ versus Numerical $\overline{\mathrm{Nu}_{\mathrm{C}}}$ in case 1 .

A high correlation coefficient of 0.9699 and a standard error of 0.1876 indicates the excellent goodness of the fit.

\section{Correlation for $\overline{\mathrm{Nu}_{\mathrm{C}}}$ in Case 2}

Based on a large set of data (approximately data 120 sets) a correlation for the $\overline{\mathrm{Nu}_{\mathrm{C}}}$ has derived as Eq. (14).

$\overline{N u_{C}}=0.2949 G r_{H}^{0.1508}\left[\frac{N_{r c}}{N_{r c}+1}\right]^{1.5873}(1+\varepsilon)^{-0.7151}(1+W)^{1.8347}$

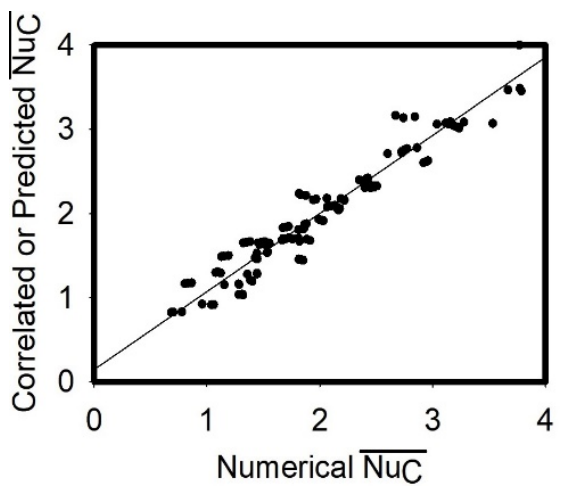

Fig. 22 Parity plot showing the goodness of fit for $\overline{\mathrm{Nu}_{\mathrm{C}}}$. Correlated $\overline{\mathrm{Nu}_{\mathrm{C}}}$ versus Numerical $\overline{\mathrm{Nu}_{\mathrm{C}}}$ in case 2 .

A high correlation coefficient of 0.9642 and a standard error of 0.2054 indicates the excellent goodness of the fit.

\section{Correlation for $\overline{\mathrm{Nu}_{\mathrm{C}}}$ in Case 3}

Based on a large set of data (approximately data 120 sets) a correlation for the $\overline{\mathrm{Nu}_{\mathrm{C}}}$ has derived as Eq. (15).

$\overline{N u_{C}}=0.0629 G r_{H}{ }^{0.2830}\left[\frac{N_{r c}}{N_{r c}+1}\right]^{2.3119}(1+\varepsilon)^{-0.6615}(1+W)^{2.5110}$

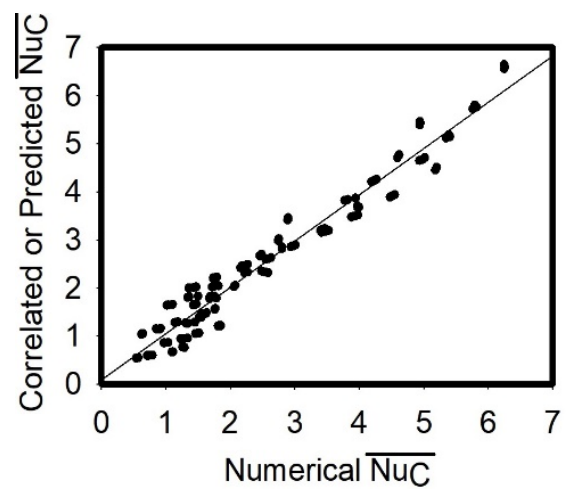

Fig. 23 Parity plot showing the goodness of fit for $\overline{\mathrm{Nu}_{\mathrm{C}}}$. Correlated $\overline{\mathrm{Nu}_{\mathrm{C}}}$ versus Numerical $\overline{\mathrm{Nu}_{\mathrm{C}}}$ in case 3 .

A high correlation coefficient of 0.9758 and a standard error of 0.3328 indicates the excellent goodness of the fit.

The Grashof Number directly influences the convective heat transfer, hence it is used in a power law form in the correlations for the $\overline{\mathrm{Nu}_{\mathrm{C}}}$. The exponent of Grashof number is positive in the correlations for $\overline{\mathrm{Nu}_{\mathrm{C}}}$. This clearly indicates that the $\overline{\mathrm{Nu}_{\mathrm{C}}}$ increases with the increase in Grashof number. $\mathrm{N}_{\mathrm{rc}}$ is a superfluous parameter for the case of study with a single fluid. In this correlation, the emissivity ' $\varepsilon$ ' and the port ratio ' $W$ ' is used as $(1+\varepsilon)$ and $(1+\mathrm{W})$, because when $\varepsilon=0$ and $\mathrm{W}=0$, even then the $\overline{\mathrm{Nu}_{\mathrm{C}}}$ is nonzero. The exponent of $(1+\varepsilon)$ is negative in the correlation for $\overline{\mathrm{Nu}_{\mathrm{C}}}$, which signifies the decrease in $\overline{\mathrm{Nu}_{\mathrm{C}}}$ with the increase in emissivity. The exponent of $(1+\mathrm{W})$ is positive in this correlation signifying the increase in $\overline{\mathrm{Nu}_{\mathrm{C}}}$ with the increase in the size of port or opening. Further it is remarkable that the exponent of $(1+\mathrm{W})$ is significantly larger in the correlation for the case 3 among the above three correlations for $\overline{\mathrm{Nu}_{\mathrm{C}}}$ in the three cases. This indicates that the presence of port or opening at the position in the case 3 is significantly more effective in enhancing the convective heat transfer from left side hot wall.

Here in all the parity plots (shown in Figs. 21, 22 and 23), we can observe that the numerical data is distributed around the parity line without any bias.

\subsection{Correlations for $\overline{\mathrm{Nu}_{\mathrm{R}}}$ in Cases 1,2 and 3}

\section{Correlation for $\overline{\mathrm{Nu}_{\mathrm{R}}}$ in Case 1}

Based on a large set of data (approximately data 120 sets) a correlation for the $\overline{\mathrm{Nu}_{\mathrm{R}}}$ has derived as Eq. (16).

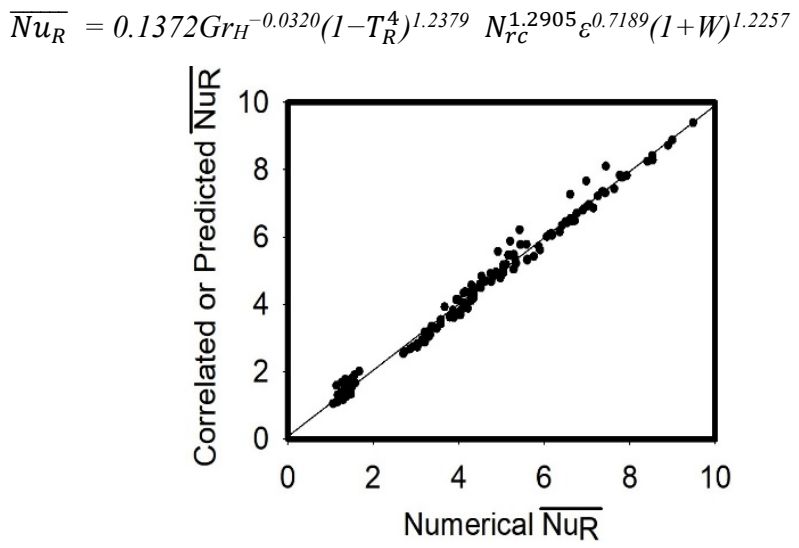

Fig. 24 Parity plot showing the goodness of fit for $\overline{\mathrm{Nu}_{\mathrm{R}}}$. Correlated $\overline{\mathrm{Nu}_{\mathrm{R}}}$ versus numerical $\overline{\mathrm{Nu}_{\mathrm{R}}}$ in case 1 .

A high correlation coefficient of 0.9939 and a standard error of 0.2418 indicates the excellent goodness of the fit. 


\section{Correlation for $\overline{\mathrm{Nu}_{\mathrm{R}}}$ in Case 2}

Based on a large set of data (approximately data 120 sets) a correlation for the $\overline{\mathrm{Nu}_{\mathrm{R}}}$ has derived as Eq. (17).

$\overline{N u_{R}}=0.7014 G r_{H}{ }^{-0.0256}\left(1-T_{R}^{4}\right)^{0.7988} N_{r c}^{0.7196} \varepsilon^{0.7059}(1+W)^{1.4670}$

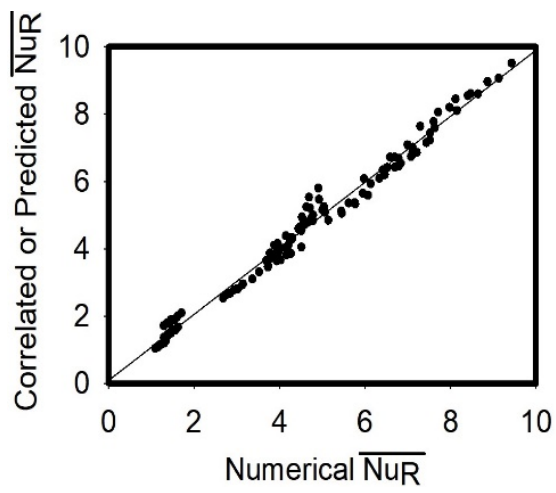

Fig. 25 Parity plot showing the goodness of fit for $\overline{\mathrm{Nu}_{\mathrm{R}}}$. Correlated $\overline{\mathrm{Nu}_{\mathrm{R}}}$ versus numerical $\overline{\mathrm{Nu}_{\mathrm{R}}}$ in case 2 .

A high correlation coefficient of 0.9930 and a standard error of 0.2734 indicates the excellent goodness of the fit.

\section{Correlation for $\overline{\mathrm{Nu}_{\mathrm{R}}}$ in Case 3}

Based on a large set of data (approximately data 120 sets) a correlation for the $\overline{\mathrm{Nu}_{\mathrm{R}}}$ has derived as Eq. (18).

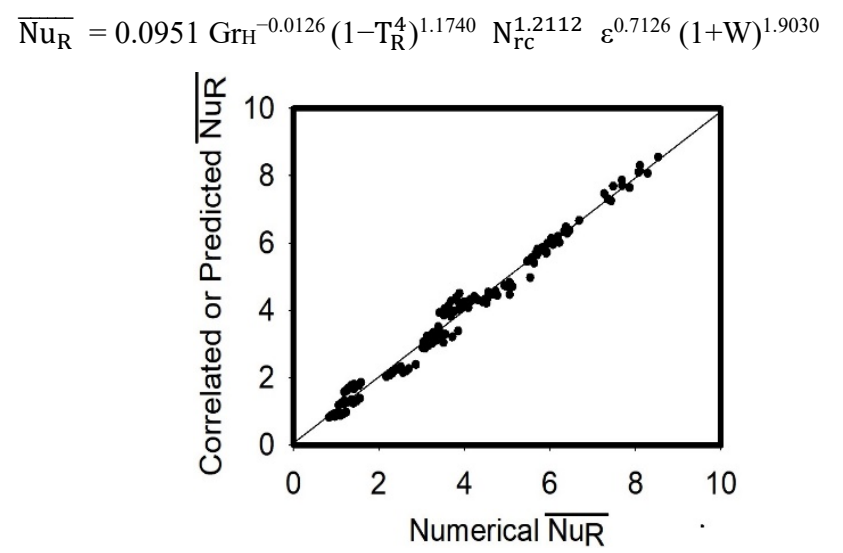

Fig. 26 Parity plot showing the goodness of fit for $\overline{\mathrm{Nu}_{\mathrm{R}}}$. Correlated $\overline{\mathrm{Nu}_{\mathrm{R}}}$ versus numerical $\overline{\mathrm{Nu}_{\mathrm{R}}}$ in case 3 .

A high correlation coefficient of 0.9928 and a standard error of 0.2521 indicates the excellent goodness of the fit.

The Grashof Number directly influences the radiative heat transfer, hence it is used in a power law form in the correlations for the $\overline{\mathrm{Nu}_{\mathrm{R}}}$. The exponent of Grashof number has a small negative value in the correlations for $\overline{\mathrm{Nu}_{R}}$. This clearly indicates that the $\overline{\mathrm{Nu}_{R}}$ decreases slightly with the increase in Grashof number. The radiant heat flux is proportional to $\left(\mathrm{T}_{\mathrm{h}}^{4}-\mathrm{T}_{\infty}^{4}\right)=\mathrm{T}_{\mathrm{h}}^{4}\left(1-\mathrm{T}_{\mathrm{R}}^{4}\right)$, where $\mathrm{T}_{\mathrm{R}}=\mathrm{T}_{\infty} / \mathrm{T}_{\mathrm{h}}$. Thus the $\overline{\mathrm{Nu}_{\mathrm{R}}}$ is correlated with $\left(1-\mathrm{T}_{\mathrm{R}}^{4}\right)$ as the power law form. The exponent of $\left(1-\mathrm{T}_{\mathrm{R}}^{4}\right)$ has a positive value indicating that $\overline{\mathrm{Nu}_{\mathrm{R}}}$ increases with the increase in the temperature of left isothermal hot wall. $\mathrm{N}_{\mathrm{rc}}$ is a superfluous parameter for the case of study with a single fluid.

With the increase in the emissivity of wall ' $\varepsilon$ ', $\overline{\mathrm{Nu}_{\mathrm{R}}}$ also increases and hence $\varepsilon$ is being used as the power law form in the correlations for $\overline{\mathrm{Nu}_{\mathrm{R}}}$. In these correlations, the port ratio ' $\mathrm{W}$ ' is used as $(1+\mathrm{W})$, because when $\mathrm{W}=0$, even then the $\overline{\mathrm{Nu}_{\mathrm{R}}}$ is nonzero. The exponent of $(1+\mathrm{W})$ is positive in this correlation signifying the increase in $\overline{\mathrm{Nu}_{\mathrm{R}}}$ with the increase in the size of port or opening.
Here in all the parity plots (shown in Figs. 24, 25 and 26), we can observe that the numerical data is distributed around the parity line without any bias.

\section{CONCLUSIONS}

Based on the above discussion, it is found that that the cooling of left isothermal hot wall is maximum, when the right side of cavity is completely open. For a fixed size of opening, better cooling of left side hot wall is observed in the case 3 . Thus it is concluded that in the cavity having the right side opening near the top wall as in case 3 have the optimal cooling among the all geometries discussed.

From the present study, the following conclusions are also made:

1. The left isothermal hot wall loses heat by natural convection and surface radiation.

2. The left isothermal hot wall loses heat to the other walls by radiative heat transfer and in turn the other walls loses heat by convective and radiative heat transfer.

3. The cavity having very small opening may have very small inadequate convective and radiative cooling of the hot wall.

4 . With the increase in port size, both the convective and radiative heat transfer in the cavity increases.

5. The dimensions of port affect the velocity and volume of fresh ambient air entering and hot air exiting at the port of cavity and thus the cooling of the left isothermal hot wall inside the cavity.

6 . The position of port on the right side wall has significant effect on streamlines and isotherms as well as on convective and radiative heat transfer from the left isothermal hot wall.

7. The presence of port at the top of right side wall is the most effective in cooling of left isothermal hot wall due to hot air escaping smoothly out of the cavity without recirculation.

8 . The convective heat transfer from the left isothermal hot wall decreases slightly with the emissivity of the cavity walls.

9. The radiative heat transfer from the left isothermal hot wall increases with the increase in emissivity of the cavity walls.

10. The heat loss from the left isothermal hot wall by natural convection and surface radiation are comparable at the higher emissivity of the cavity walls.

11. The circulation of air is weak at the central part of the cavity in almost all the cases.

12. There secondary air circulations may be present at the corners of cavity affecting the cooling of left isothermal hot wall and other adiabatic walls of the cavity.

\section{NOMENCLATURE}

A aspect ratio $=\mathrm{H} / \mathrm{d}$

$d \quad$ spacing between left and right walls (m)

$F_{i, \mathrm{j}} \quad$ shape factor between the elements $\mathrm{i}$ and $\mathrm{j}$

$g \quad$ acceleration due to gravity $\left(9.81 \mathrm{~m} \cdot \mathrm{s}^{-2}\right)$

$G \quad$ dimensionless elemental irradiation

$\mathrm{Gr}_{H} \quad$ Grashof Number (based on $\mathrm{H}$ )

$=\mathrm{g} \beta\left(\mathrm{T}_{\mathrm{h}}-\mathrm{T}_{\infty}\right) \mathrm{H}^{3} / v^{2}$

$H \quad$ height of the cavity (m)

$J \quad$ dimensionless elemental radiosity

$\mathrm{k}$ thermal conductivity of dry air $\left(\mathrm{W} \cdot \mathrm{m}^{-1} \cdot \mathrm{K}^{-1}\right)$

$m$ total number of grid points in horizontal $\mathrm{Y}$ direction in the computational domain

$n$ total number of grid points in vertical $\mathrm{X}$ direction in the computational domain

$N_{r c} \quad$ radiation-conduction parameter

$=\mathrm{N}_{\mathrm{rc}}=\sigma \mathrm{T}_{\mathrm{h}}{ }^{4} /\left[\mathrm{k}\left(\mathrm{T}_{\mathrm{h}}-\mathrm{T}_{\infty}\right) / \mathrm{d}\right]$

$\mathrm{NuC} \quad$ convection Nusselt number

$\overline{N u_{C}} \quad$ average convection Nusselt number (ANUC)

$N u_{R} \quad$ radiation Nusselt number

$\overline{N u_{R}} \quad$ average radiation Nusselt number (ANUR) 


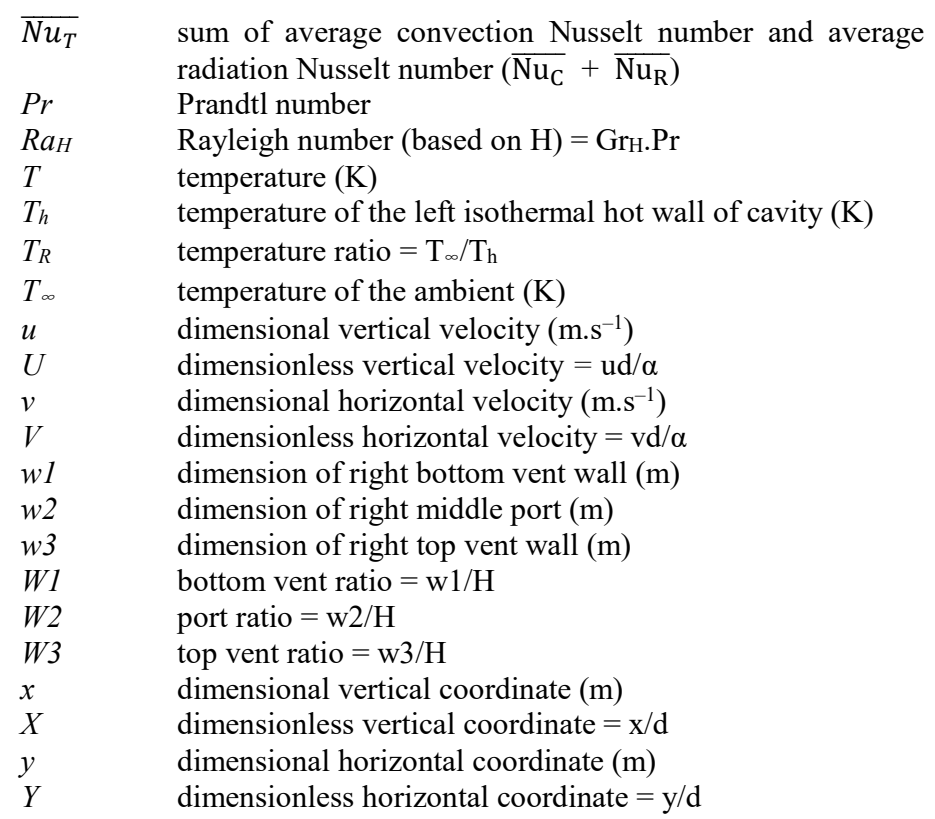

\section{Greek Symbols}

$\alpha \quad$ thermal diffusivity of fluid $\left(\mathrm{m}^{2} \cdot \mathrm{s}^{-1}\right)$

$\beta \quad$ isobaric co-efficient of volumetric thermal expansion of

$\delta \quad$ convergence parameter in percentage

$=\left|\left(\zeta_{\text {new }}-\zeta_{\text {old }}\right) / \zeta_{\text {new }}\right| X 100$

$\varepsilon \quad$ emissivity of the walls

$\zeta \quad$ symbol for the any dependent variable $(\psi, \omega, \theta, \mathrm{J}, \mathrm{G})$ over which convergence test is being applied

$\theta \quad$ dimensionless temperature $=\left(\mathrm{T}-\mathrm{T}_{\infty}\right) /\left(\mathrm{T}_{\mathrm{h}}-\mathrm{T}_{\infty}\right)$

$v \quad$ kinematic viscosity of the fluid $\left(\mathrm{m}^{2} \cdot \mathrm{s}^{-1}\right)$

$\sigma \quad$ Stefan Boltzmann constant $\left(5.67 \times 10^{-8} \mathrm{~W} \cdot \mathrm{m}^{-2} \cdot \mathrm{K}^{-4}\right)$

$\psi^{\prime} \quad$ dimensional stream function $\left(\mathrm{m}^{2} \cdot \mathrm{s}^{-1}\right)$

$\psi \quad$ dimensionless stream function $=\psi^{\prime} / \alpha$

$\omega^{\prime} \quad$ dimensional vorticity $\left(\mathrm{s}^{-1}\right)$

$\omega \quad$ dimensionless vorticity $=\omega^{\prime} \mathrm{d}^{2} / \mathrm{v}$

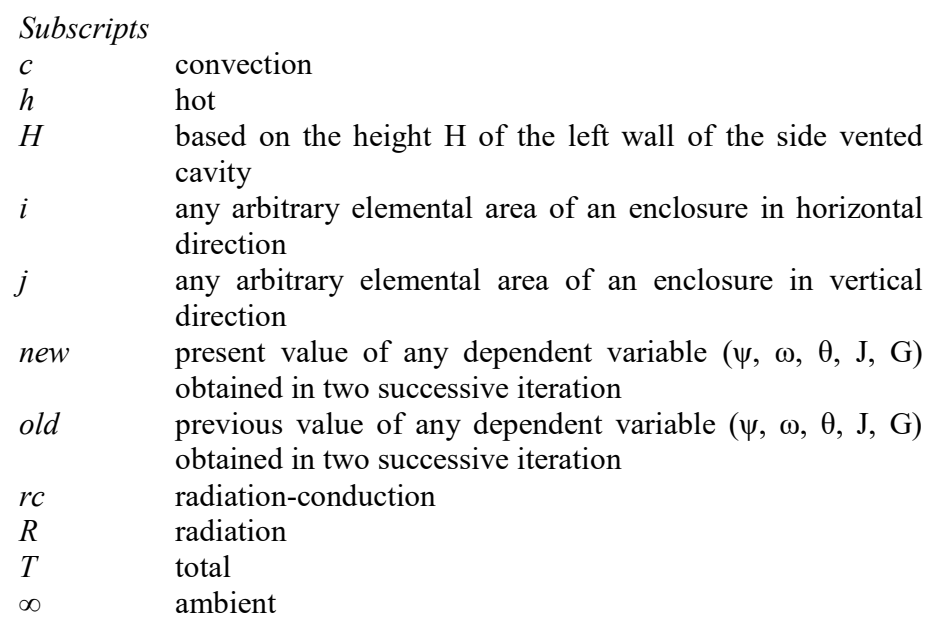

\section{REFERENCES}

Abib, A.H., and Jaluria, Y., 1988, "Numerical simulation of the buoyancy-induced flow in a partially open enclosure," Numerical Heat Transfer, 14(2), 235-254.

http://dx.doi.org/10.1080/10407788808913642
Balaji, C., and Venkateshan, S.P., 1994a, "Correlations for free convection and surface radiation in a square cavity," International Journal of Heat and Fluid Flow, 15(3), 249-251. http://dx.doi.org/10.1016/0142-727X(94)90046-9

Balaji, C., and Venkateshan, S.P., 1994b, "Interaction of radiation with free convection in an open cavity," International Journal of Heat and Fluid Flow, 15(4), 317-324.

http://dx.doi.org/10.1016/0142-727X(94)90017-5

Bangian-Tabrizi, Ardeshir, Jaluria, Yogesh, 2018, An optimization strategy for the inverse solution of a convection heat transfer problem, International Journal of Heat and Mass Transfer, 124, 1147-1155. http://dx.doi.org/10.1016/j.ijheatmasstransfer.2018.04.053

Bilgen, E., and Oztop, H., 2005, "Natural convection heat transfer in partially open inclined square cavities," International Journal of Heat and Mass Transfer, 48(8), 1470-1479.

http://dx.doi.org/10.1016/j.ijheatmasstransfer.2004.10.020

Bilgen, E., and Muftuoglu, A., 2008, "Natural convection in an open square cavity with slots," International Communications in Heat and Mass Transfer, 35(8), 896-900.

http://dx.doi.org/10.1016/j.icheatmasstransfer.2008.05.001

Chan, Y.L., and Tien, C.L., 1985, "A numerical study of twodimensional natural convection in square open cavities," Numerical Heat Transfer, 8(1), 65-80.

http://dx.doi.org/10.1080/01495728508961842

Gnanasekaran, N., Balaji, C., 2011, “A correlation for Nusselt number under turbulent mixed convection using transient heat transfer experiments," Frontiers in Heat and Mass Transfer, 2, 023008.

http://dx.doi.org/10.5098/hmt.v2.2.3008

Gonzalez, Moises Montiel, Palafox, Jesus Hinojosa, and Estrada, Claudio A., 2012, "Numerical study of heat transfer by natural convection and surface thermal radiation in an open cavity receiver," Solar Energy, 86(4), 1118-1128.

http://dx.doi.org/10.1016/i.solener.2012.01.005

González, M. Montiel, Hinojosa, J.F., Villafán-Vidales, H.I., BautistaOrozco, A., and Estrada, C.A., 2015, "Theoretical and experimental study of natural convection with surface thermal radiation in a side open cavity," Applied Thermal Engineering, 75, 1176-1186. http://dx.doi.org/10.1016/j.applthermaleng.2014.05.047

Hati, Mourad, Raji, Abdelghani, Hasnaoui, Mohammed, Naïmi, Mohamed, and Abdallaoui, Mohamed El, 2017, "Optimal Natural Convection Heat Transfer Improvement by Combining Periodic Heating Temperature, Cavity Inclination, and Nanofluid," Heat Transfer Engineering, 38(10), 931-947.

http://dx.doi.org/10.1080/01457632.2016.1212574

Hinojosa, J.F., Estrada, C.A., Cabanillas, R.E., and Alvarez, G., 2005, "Numerical study of transient and steady-state natural convection and surface thermal radiation in a horizontal square open cavity," Numerical Heat Transfer, Part A, 48(2), 179-196.

http://dx.doi.org/10.1080/10407780590948936

Joo, Younghwan, Kim, Sung Jin, 2016, "Thermal optimization of vertically oriented, internally finned tubes in natural convection," International Journal of Heat and Mass Transfer, 93, 991-999. http://dx.doi.org/10.1016/j.ijheatmasstransfer.2015.10.034

Karami, Alimohammad, Veysi, Farzad, Mohebbi, Saeed, and Ghashghaei, Damoon, 2014, "Optimization of Laminar Free Convection in a Horizontal Cavity Consisting of Flow Diverters Using ICA," Arabian Journal for Science and Engineering, 39(3), 2295-2306. http://dx.doi.org/10.1007/s13369-013-0741-8 
Karatas, Hakan, and Derbentli, Taner, 2017, "Three-dimensional natural convection and radiation in a rectangular cavity with one active vertical wall," Experimental thermal and fluid science, 88, 277-287. http://dx.doi.org/10.1016/j.expthermflusci.2017.05.025

Kasayapanand, Nat, 2007, "Numerical modeling of natural convection in partially open square cavities under electrical field," International Communications in Heat and Mass Transfer, 34(5), 630-643. http://dx.doi.org/10.1016/j.icheatmasstransfer.2007.02.008

Li, Hua, and Tong, Shanshan, 2016, Natural convective heat transfer in the inclined rectangular cavities with low width-to-height ratios, International Journal of Heat and Mass Transfer, 93, 398-407. http://dx.doi.org/10.1016/j.ijheatmasstransfer.2015.10.027

Lugarini, Alan, Franco, Admilson T., Junqueira, Silvio L.M., and Lage, José L., 2018, "Natural Convection and Surface Radiation in a Heated Wall, C-Shaped Fracture," Journal of Heat Transfer, 140(8), 082501. http://dx.doi.org/10.1115/1.4039643

Martyushev, Semen G., and Sheremet, Mikhail A., 2014, "Conjugate natural convection combined with surface thermal radiation in an air filled cavity with internal heat source," International Journal of Thermal Sciences, 76, 51-67.

https://dx.doi.org/10.1016/i.ijthermalsci.2013.08.012

Miroshnichenko, Igor V., and Sheremet, M. A., 2015. "Numerical simulation of turbulent natural convection combined with surface thermal radiation in a square cavity," International Journal of Numerical Methods for Heat \& Fluid Flow, 25(7), 1600-1618.

https://dx.doi.org/10.1108/HFF-09-2014-0289

Miroshnichenko, Igor V., and Sheremet, Mikhail A., 2018, "Turbulent natural convection combined with thermal surface radiation inside an inclined cavity having local heater," International Journal of Thermal Sciences, 124, 122-130.

http://dx.doi.org/10.1016/i.ijthermalsci.2017.09.023

Mohamad, A.A., 1995, "Natural convection in open cavities and slots," Numerical Heat Transfer, Part A, 27(6), 705-716.

http://dx.doi.org/10.1080/10407789508913727

Nouanegue, H., Muftuoglu, A., Bilgen, E., 2008, "Conjugate heat transfer by natural convection, conduction and radiation in open cavities," International Journal of Heat and Mass Transfer, 51(25-26), 6054-6062. http://dx.doi.org/10.1016/j.ijheatmasstransfer.2008.05.009

Palafox, J.F. Hinojosa, 2012, "Numerical study of the natural convection in a two-dimensional partially open tilted cavity," Latin American Applied Research, 42(3), 267-274.

http://www.scielo.org.ar/scielo.php?pid=S0327$\underline{07932012000300008 \& \text { script }=\text { sci abstract }}$

(Accessed on September 12, 2018).

Panda, Rajesh Kumar, Prasad, B.V.S.S.S., 2011, "Conjugate heat transfer from a flat plate with shower head impinging jets," Frontiers in Heat and Mass Transfer, 2, 013008.

http://dx.doi.org/10.5098/hmt.v2.1.3008

Poovanan, A., Mageshwaran, G., Durai Raj, R. B., Karthik, M. K. Dilipan, and Hariharan, V., 2018, "Heat sink elimination and optimisation by natural convection method," International Journal of Ambient Energy.

http://dx.doi.org/10.1080/01430750.2017.1392355
Prasad, Ravi Shankar; Singh, S.N., and Gupta, Amit Kumar, 2018, “A systematic approach for optimal positioning of heated side walls in a side vented open cavity under natural convection and surface radiation," Frontiers in Heat and Mass Transfer, 11, 15. http://doi.org/10.5098/hmt.11.15

Rao, C. Gururaja, Balaji, C. and Venkateshan, S.P., 2000, "Conjugate mixed convection with surface radiation from a vertical plate with discrete heat source," Journal of Heat Transfer, 123(4), 698-702. http://dx.doi.org/10.1115/1.1373654

Saglietti, Clio, Schlatter, Philipp, Monokrousos, Antonios, and Henningson, Dan S., 2017, "Adjoint optimization of natural convection problems: differentially heated cavity," Theoretical and Computational Fluid Dynamics, 31(5-6), 537-553.

http://dx.doi.org/10.1007/s00162-016-0398-5

Sheremet, Mikhail A., and Miroshnichenko, Igor V., 2016. Effect of surface radiation on transient natural convection in a wavy-walled cavity. Numerical Heat Transfer, Part A: Applications, 69(4), 369-382. https://dx.doi.org/10.1080/10407782.2015.1080577

Singh, Dwesh K., and Singh, S.N., 2015, "Conjugate free convection with surface radiation in open top cavity," International Journal of Heat and Mass Transfer, 89, 444-453.

http://dx.doi.org/10.1016/j.ijheatmasstransfer.2015.05.038

Singh, S.N., and Venkateshan, S.P., 2004a, "Numerical study of natural convection with surface radiation in side-vented open cavities," International Journal of Thermal Sciences, 43(9), 865-876.

http://dx.doi.org/10.1016/j.ijthermalsci.2004.01.002

Singh, S.N., and Venkateshan, S.P., 2004b, "Natural convection with surface radiation in partially open cavities," International Journal Heat and Technology, 22(2), 57-64.

http://iieta.org/Journals/IJHT/ARCHIVE/Vol\%2022\%2C\%20No\%202 $\% 2 \mathrm{C} \% 202004$

(Accessed on September 12, 2018).

Singh, S.N., 2008, Numerical study of combined natural convection, conduction and surface radiation heat transfer in open top, side vented cavities, International Journal Heat and Technology, 26(2), 101-109.

http://iieta.org/Journals/IJHT/ARCHIVE/Vol\%2026\%2C\%20No\%202 $\% 2 \mathrm{C} \% 202008$

(Accessed on September 12, 2018).

Skok, H., Ramadhyani, S., and Schoenhals, R.J., 1991, "Natural convection in a side-facing open cavity," International Journal of Heat and Fluid Flow, 12(1), 36-45.

http://dx.doi.org/10.1016/0142-727X(91)90006-H

Sparrow, E.M., and Gregg, J.L., 1956, "Laminar free convection from a vertical plate with uniform surface heat flux," ASME Journal of Heat Transfer, 78(1), 435-440.

Wu, W., Ewing, D., and Ching, C.Y., 2008, "Investigation of a large top wall temperature on the natural convection plume along a heated vertical wall in a square cavity," International Journal of Heat and Mass Transfer, 51(7-8), 1551-1561. http://dx.doi.org/10.1016/j.ijheatmasstransfer.2007.07.022 